\title{
Petrografia, química mineral e processos hidrotermais associados ao depósito de ouro São Jorge, Província Aurífera do Tapajós, Cráton Amazônico
}

\author{
Régis Munhoz Krás Borges ${ }^{1}$, Roberto Dall'Agnol', Claudio Nery Lamarão' ${ }^{1}$, \\ Marco Aurélio Benevides Maia Figueiredo', Albano Antônio da Silva Leite ${ }^{2}$, \\ Carlos Eduardo de Mesquita Barros ${ }^{3}$ \& Hilton Túlio Costi ${ }^{4}$
}

\begin{abstract}
Resumo O depósito de ouro São Jorge, de idade paleoproterozóica, está situado na Província Aurífera do Tapajós, Cráton Amazônico. Ele está hospedado em um anfibólio-biotita-monzogranito constituído por quartzo, feldspato potássico, plagioclásio, anfibólio, biotita, titanita e opacos. Quatro associações minerais foram reconhecidas no depósito. A associação 1, formada durante o estágio magmático, é caracterizada pela presença de anfibólio e andesina-oligoclásio. A associação 2 mostra substituição total do anfibólio e intensa saussuritização do plagioclásio primário; o epidoto é uma fase marcante e a biotita é parcialmente cloritizada. As associações 3 e 4 estão relacionadas aos processos hidrotermais que geraram a mineralização de sulfeto e ouro. A assembléia 3 é dominada por clorita e plagioclásio albítico, com quantidade subordinada de mica branca e, por vezes, biotita. A associação 4 é dominada por mica branca, pirita e carbonatos sendo o resultado de uma alteração fílica com carbonatação associada. O geotermômetro da clorita sugere temperaturas de $300 \pm 40{ }^{\circ} \mathrm{C}$ para as associações 3 e 4 . O geobarômetro do $\mathrm{Al}$ na hornblenda indica pressões em torno de 1 kbar para a cristalização dos granitos mineralizados. Condições oxidantes, acima do tampão NNO, prevaleceram durante a gênese dos depósitos. As associações hidrotermais de São Jorge diferem daquelas descritas nos garimpos Joel e Davi e não são dominadas por epidoto, como sugerido em outras áreas da Província Tapajós. Um modelo pórfiro ou intrusion-related são melhor adaptados para o depósito São Jorge. Este último tem similaridades com o depósito Serrinha da Província Juruena e Batalha, na Província Tapajós, e fortes analogias com o sistema hidrotermal Volta Grande no sul do Brasil.
\end{abstract}

Palavras-chave: processos hidrotermais, química mineral, Granito São Jorge Jovem, Província Aurífera do Tapajós.

\begin{abstract}
Petrography, mineral chemistry, and hydrothermal processes associated with the São Jorge gold deposit, Tapajós Gold Province, Amazonian Craton. The Paleoproterozoic São Jorge gold deposit is situated in the Tapajós Gold Province of the Amazonian Craton. The deposit is hosted by an amphibole biotite monzogranite, composed of quartz, potassic feldspar, plagioclase, amphibole, biotite, titanite and opaques. Four dominant mineral assemblages were recognized in the deposit. Assemblage 1 was formed during the magmatic stage and is characterized by the presence of amphibole and andesineoligoclase. Assemblage 2 shows the total replacement of the amphibole and intense saussuritization of the primary plagioclase, epidote is a ubiquitous phase and biotite is partially chloritized. Assemblages 3 and 4 are related to the hydrothermal processes, which generated the sulfide and gold mineralization. Assemblage 3 is dominated by chlorite and albitic plagioclase with subordinate white micas and, sometimes, biotite. Assemblage 4 is dominated by white micas, carbonates and pyrite. It is a result of a phyllic alteration, with associated carbonatization. Chlorite geothermometer suggests temperatures of $300 \pm 40{ }^{\circ} \mathrm{C}$ for the 3 and 4 assemblages. $\mathrm{Al}$ in hornblende geobarometer indicates low pressures, around $1 \mathrm{kbar}$ for the crystallization of the mineralized granites. Oxidizing conditions, above NNO, prevailed during the genesis of the deposit. The hydrothermal assemblages of São Jorge differ from those described at Joel and Davi and are not dominated by epidote minerals as registered in other areas of the Tapajós province. A porphyry model or intrusionrelated model are best adapted for the São Jorge deposit. The latter has similarities with the Serrinha deposit in the Juruena province and Batalha in the Tapajós province but it has more strong analogies with the Volta Grande hydrothermal system in southern Brazil.
\end{abstract}

Keywords: hydrothermal processes, mineral chemistry, Younger São Jorge granite, Tapajós Gold Province.

1 - Universidade Federal do Pará, Grupo de Pesquisa Petrologia de Granitóides, Belém (PA), Brasil. E-mails: munhoz@ufpa.br, lamarao@ufpa.br, robdal@ufpa.br

2 - Vale, Centro de Desenvolvimento Mineral, Santa Luzia (MG), Brasil. E-mail: albano.leite@vale.com

3 - Universidade Federal do Paraná, Curitiba (PR), Brasil. E-mail: cadubarros@ufpr.br

4 - Museu Paraense Emílio Goeldi, Belém (PA), Brasil. E-mail: tulio@museu-goeldi.br 
INTRODUÇÃOO O depósito aurífero São Jorge, hospedado pelo Granito São Jorge Jovem (Lamarão 2001), foi alvo de intensa prospecção mineral pela empresa Rio Tinto Desenvolvimentos Minerais Ltda. (RTDM), que executou um extenso programa de sondagem rotativa na área situada no garimpo homônimo.

A PAT (Faraco et al. 1997) tem-se caracterizado desde a década de 1970 como uma das principais produtoras de ouro do Brasil. A quase totalidade da produção da província foi extraída de depósitos secundários por garimpeiros (produção estimada não oficial de 600 toneladas). Na década de 1990, esses depósitos começaram a se exaurir, o que, aliado a outros problemas conjunturais, causou uma acentuada queda na produção da província. Foi incrementada neste período a prospecção de jazidas primárias de ouro por diversas empresas, ao mesmo tempo em que era retomado o mapeamento geológico regional através da CPRM. Esse esforço gerou uma série de informações importantes para o avanço do conhecimento do contexto geológico (Klein \& Vasquez 2000, Vasquez et al. 1999, Almeida et al. 2000, Santos et al. 2000, 2004, Lamarão et al. 2002, 2005) e metalogênese (Coutinho et al. 2000, Dreher et al. 1998, Jacobi 1999, Santos et al. 2001, Nunes 2001, Juliani et al. 2002, 2004a, 2004b, 2005, Landis et al. 2005) da província. Restaram, porém, grandes lacunas no que tange aos estudos detalhados dos depósitos existentes na província e aos processos responsáveis pela geração dos mesmos.

Os estudos de processos hidrotermais associados com mineralizações de ouro em granitos do Brasil cresceram significativamente (Botelho \& Moura 1998, Tallarico et al. 2004, Botelho et al. 2005, Lindenmayer et al. 2005, Moura et al. 2006), porém permanecem escassos na Província do Tapajós. O presente trabalho visa a contribuir para a caracterização de tais processos na PAT, mais especificamente no depósito São Jorge, discutindo suas relações com as mineralizações auríferas associadas e possíveis modelos para a gênese do depósito.

\section{GEOLOGIA E GEOCRONOLOGIA DO GRANI-} TO SÃO JORGE O Granito São Jorge foi identificado por Lamarão (2001) na região de Vila Riozinho, Província Aurífera do Tapajós (PAT).

A PAT está localizada na porção central do Cráton Amazônico, e situa-se no limite entre as províncias Ventuari-Tapajós (ou Tapajós-Parima, Santos et al. 2000) e Amazônia Central (Tassinari \& Macambira 1999), sendo caracterizada por um extenso magmatismo vulcano-plutônico paleoproterozóico (Klein \& Vasquez 2000, Lamarão et al. 2002, Santos et al. 2000, 2004).

A localidade de Vila Riozinho, situada na porção leste da PAT, a $300 \mathrm{~km}$ a sul da cidade de Itaituba (PA), é acessada pela rodovia Cuiabá-Santarém.

A figura 1 apresenta o mapa geológico da região de Vila Riozinho, onde pode ser visualizada a distribuição das diferentes unidades geológicas aí identificadas (Lamarão et al. 2002). Detalhes sobre a geologia regional podem ser acessadas em Lamarão \& Dall'Agnol (2004).

Lamarão et al. (2002) demonstraram que o corpo granítico São Jorge é formado por dois granitos distintos.
Um deles, com idades $\mathrm{Pb}-\mathrm{Pb}$ em zircão de $1981 \pm 9 \mathrm{Ma}$ e $1981 \pm 2 \mathrm{Ma}$, constitui a maior parte do corpo, tendo sido designado como Granito São Jorge Antigo (GSJA). O segundo, com idade $\mathrm{Pb}-\mathrm{Pb}$ em zircão de $1891 \pm 3 \mathrm{Ma}$, foi denominado Granito São Jorge Jovem (GSJJ) e está intimamente associado com o depósito aurífero São Jorge, ocorrendo em subsuperfície na zona mineralizada e em exposições localizadas em superfície.

Granito São Jorge Antigo O GSJA é um corpo irregular, de dimensões batolíticas, formado por rochas pouco deformadas, geralmente isótropas. Ele aflora nos arredores e a sul de Vila Riozinho, bem como ao longo do rio Jamanxim e margeando o Riozinho das Arraias (Fig. 1). A distribuição espacial das diferentes fácies identificadas (Fig. 1) sugere que o GSJA é composicionalmente zonado. Localmente, nas bordas nordeste, noroeste e oeste, afloram rochas monzodioríticas a quartzo-monzodioríticas. Nas porções leste e norte tem-se um domínio de anfibólio-biotita-monzogranito, com anfibólio-biotita-quartzo-monzonito subordinado, o qual constitui a fácies dominante no corpo. Nas áreas central e sul do corpo estão expostos biotita-leucomonzogranitos a sienogranitos que constituem a fácies mais evoluída do corpo (Fig. 1).

$\mathrm{Na}$ parte central deste corpo, em uma área rebaixada topograficamente, recoberta por espesso manto de intemperismo, localiza-se o depósito São Jorge. Neste local foi identificado em subsuperfície o GSJJ, petrograficamente semelhante ao GSJA, porém com características geoquímicas contrastantes e idade $\mathrm{Pb}-\mathrm{Pb}$ em zircão mais jovem.

Granito São Jorge Jovem O GSJJ foi estudado com base nos testemunhos de sondagem dos furos realizados na área mineralizada (Fig. 2), e a sul de Vila Riozinho, onde aflora na forma de grandes blocos. Em testemunhos de sondagem da área mineralizada, nas porções menos afetadas pelos processos hidrotermais, apresenta coloração acinzentada e mineralogia e feições texturais similares às identificadas no GSJA. Nos afloramentos a sul de Vila Riozinho, mostra-se hidrotermalizado e com coloração avermelhada, sendo formado dominantemente por quartzo, feldspato alcalino e plagioclásio. A fácies petrográfica predominante do GSJJ é um anfibólio-biotita-monzogranito cinza, de granulação média, constituído por feldspato alcalino, plagioclásio (andesina sódica a oligoclásio), quartzo, biotita, anfibólio, titanita e opacos.

ASPECTOS GEOLÓGICOS DA ZONA MINERALIZADA A zona mineralizada corresponde à cava do antigo garimpo São Jorge (Fig. 2). Na área de mais baixo relevo, situada em torno da cava, os afloramentos são muito escassos, mas aparentemente correspondem a exposições dos biotita-leucomonzogranitos a sienogranitos aflorantes na porção central do corpo São Jorge. Esta fácies tem uma distribuição expressiva em torno da área mineralizada, mas não foi identificada nos testemunhos de sondagens. Muito localmente, mais distante da área mineralizada, foram identificados 


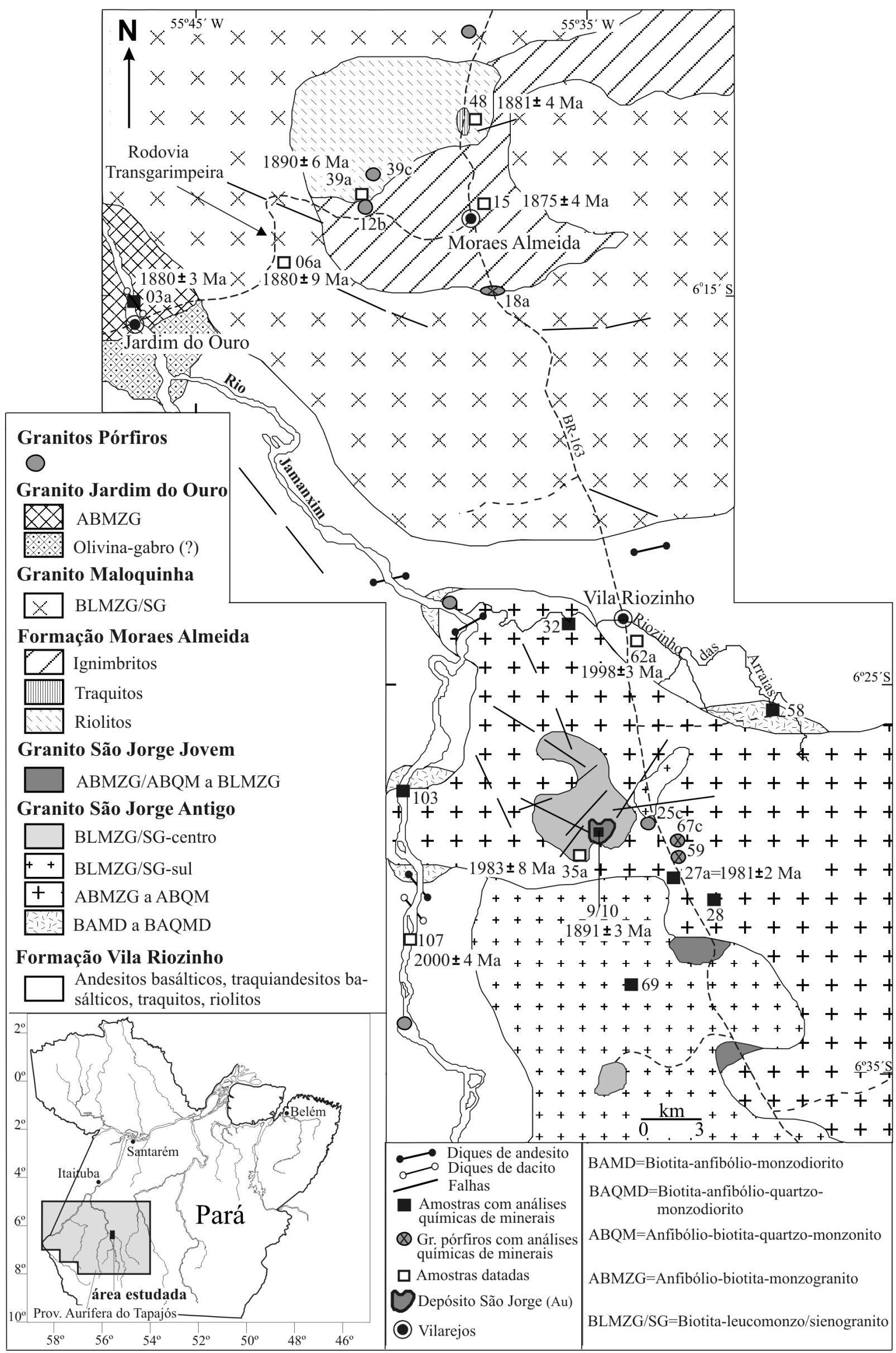

Figura 1 - Mapa geológico da região de Vila Riozinho, mostrando a distribuição das unidades geológicas e seu posicionamento estratigráfico (cf. Lamarão et al. 2002, modificado). 


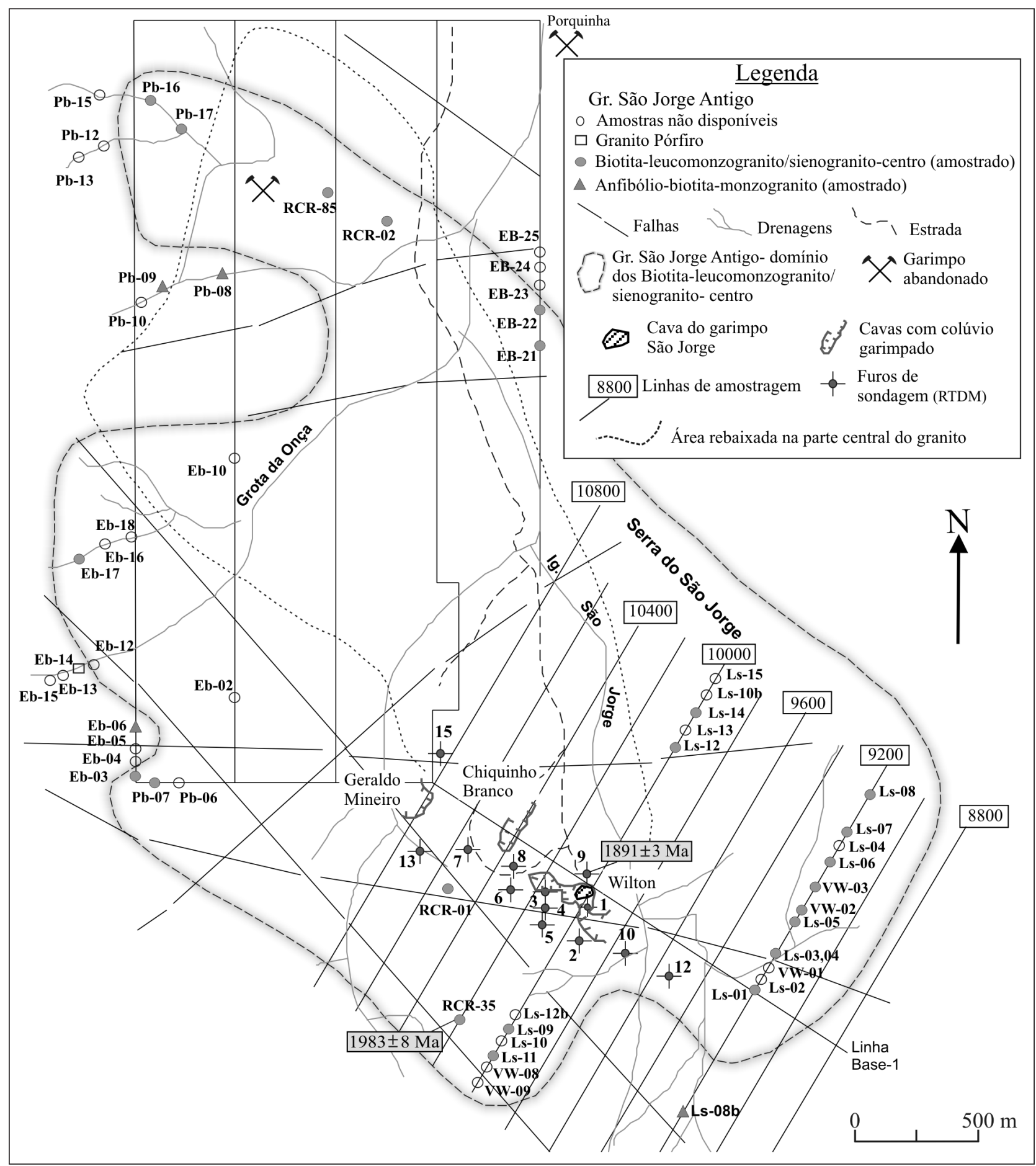

Figura 2 - Detalhe da cava do depósito São Jorge, onde foi executada a malha de sondagem rotativa pela RTDM (a sul da área), correspondendo à zona mineralizada do Granito São Jorge Jovem (Lamarão et al. 2002).

anfibólio-biotita-monzogranitos e granitos pórfiros (Fig. 1), similares petrograficamente aos descritos em outras porções do corpo e interpretados como pertencentes ao GSJA. Na área mineralizada, o GSJJ foi identificado apenas nas amostras provenientes dos furos de sondagem.

A RTDM realizou 15 furos de sondagem cobrindo inteiramente a área mineralizada (Fig. 2). Esses furos atingiram profundidades em torno de 150 a 200 metros e tiveram disposição inclinada com ângulos de $50^{\circ}$ a $55^{\circ} \mathrm{e}$ mergulhos dominantemente para norte ou, eventualmente, leste ou sul. A zona mineralizada, conforme observado em testemunhos de sondagem, encontra-se intensamente fraturada e hidrotermalizada. Os testemunhos de sondagem dos furos 2, 4, 6, 7 e 9 foram selecionados para amostragem sistemática e estudos mineralógicos, geoquímicos e metalogenéticos. As rochas dos três primeiros furos mostram-se mais intensamente hidroterma- 
lizadas, enquanto que aquelas do furo 9 são as menos afetadas pelos processos hidrotermais e, conseqüentemente, as menos intensamente mineralizadas.

Os estudos petrográficos realizados nos vários furos demonstam que: (1) A fácies predominante é um hornblenda-biotita-monzogranito com granulação média e cor cinza, passando a cinza rosado e rosado quando ligeiramente alterado. Apresenta enclaves máficos, arredondados e centimétricos, e textura rapakivi localizada; (2) nas zonas hidrotermalizadas esse granito passa a apresentar uma cor vermelha, mas preserva a sua textura ígnea; (3) nas porções mais intensamente hidrotermalizadas a rocha adquire uma coloração rosa esverdeada a verde claro e as feições texturais e mineralógicas do granito são obliteradas, havendo proporções modais expressivas de micas brancas e carbonatos, por vezes acompanhados de clorita ou biotita secundária. Nessas zonas são muito frequentes as vênulas preenchidas por tais minerais e, eventualmente, quartzo, sendo também observada a formação de brechas. Os corpos de minério sulfetado com ouro associado são constituídos essencialmente por pirita e concentram-se nessas zonas. Podem ocorrer preenchendo veios ou disseminados na rocha, associados com os demais minerais hidrotermais, com destaque para as micas brancas e carbonatos; (4) No furo 9, são comuns veios decimétricos a métricos de granito aplítico de granulação fina e cor rosa a esbranquiçada cortando o hornblenda-biotitamonzogranito.

\section{PETROGRAFIA E ASSOCIAÇÕES MINERAIS} DAS ROCHAS DAÁREA MINERALIZADA Para uma melhor caracterização dos processos hidrotermais que afetaram o granito hospedeiro das mineralizações auríferas, foram definidas quatro associações minerais representativas dos diferentes estágios de evolução das rochas estudadas. Inicia-se, portanto, com as rochas magmáticas com elevado grau de preservação, estendendo-se até aquelas que tiveram sua mineralogia e texturas inteiramente modificadas, representativas dos estágios de maior alteração hidrotermal. Subtipos petrográficos foram assinalados por letras. As fases minerais marcadoras dos diferentes estágios de evolução e a distribuição das associações mineralógicas são fornecidas na tabela 1. Segue a descrição dessas associações:

Associação 1 (estágio magmático) Definida pela presença de anfibólio juntamente com biotita marrom (biotita 1), ambas formando cristais subautomorfos a automorfos com mais de $1 \mathrm{~mm}$, plagioclásio (andesina sódica a oligoclásio; $\mathrm{An}_{32-12}$ ) com zoneamento marcante, magnetita e titanita automorfos a subautomorfos

Tabela 1 - Principais associações minerais representativas dos diferentes estágios de evolução das rochas do depósito São Jorge.

\begin{tabular}{|c|c|c|c|c|}
\hline Associações Minerais & $\begin{array}{l}\text { Associação 1: } \\
\text { Magmática }\end{array}$ & $\begin{array}{c}\text { Associação 2: } \\
\text { Magmática } \\
\text { Modificada }\end{array}$ & $\begin{array}{l}\text { Associação 3: } \\
\text { Hidrotermal }\end{array}$ & $\begin{array}{c}\text { Associação 4: } \\
\text { Hidrotermal } \\
\text { Mineralizada }\end{array}$ \\
\hline $\begin{array}{l}\text { Sequência dos estágios } \\
\text { evolutivos }\end{array}$ & Estágio magmático & $\begin{array}{l}\text { Estágio de alteração pós- } \\
\text { magmática precoce }\end{array}$ & $\begin{array}{l}\text { Estágio de alteração } \\
\text { propilítica }\end{array}$ & Estágio de alteração fílica \\
\hline \multicolumn{5}{|l|}{ Quartzo } \\
\hline \multicolumn{5}{|l|}{ Feldspato potássico } \\
\hline \multicolumn{5}{|l|}{ Plagioclásio (And-Olig) } \\
\hline \multicolumn{5}{|l|}{$\begin{array}{l}\text { Plagioclásio } \\
\text { (descalcificado ou reordenado) }\end{array}$} \\
\hline \multicolumn{5}{|l|}{ Anfibólio } \\
\hline \multicolumn{5}{|l|}{ Biotita 1} \\
\hline \multicolumn{5}{|l|}{ Biotita 2} \\
\hline \multicolumn{5}{|l|}{ Biotita 3} \\
\hline \multicolumn{5}{|l|}{ Titanita } \\
\hline \multicolumn{5}{|l|}{ Magnetita } \\
\hline \multicolumn{5}{|l|}{ Ilmenita } \\
\hline \multicolumn{5}{|l|}{ Zircão } \\
\hline \multicolumn{5}{|c|}{--------} \\
\hline \multicolumn{5}{|c|}{ Saussuritização } \\
\hline \multicolumn{5}{|l|}{ Clorita } \\
\hline \multicolumn{5}{|r|}{ Carbonatacão } \\
\hline Mica branca & & & & Sericitização \\
\hline Pirita & & & & Sulfetação \\
\hline Temperatura estimada & $\geq 700^{\circ} \mathrm{C}$ & $450-350^{\circ} \mathrm{C}$ & $340-280^{\circ} \mathrm{C}$ & $\leq 300^{\circ} \mathrm{C}$ \\
\hline Marcadores mineralógicos & $\begin{array}{l}\text { Hornblenda + } \\
\text { Plag. (And-Olig) }\end{array}$ & Biotita $1+$ Epidoto & $\begin{array}{c}\text { Clorita + Plag. } \\
\text { descalcif. + Biotita } 2\end{array}$ & $\begin{array}{c}\text { Mica branca + Carbonatos }+ \\
\text { Pirita + Biotita } 3+\text { Clorita }\end{array}$ \\
\hline Estilo de alteração & & Não penetrativo & Pervasivo & Pervasivo a fissural \\
\hline
\end{tabular}



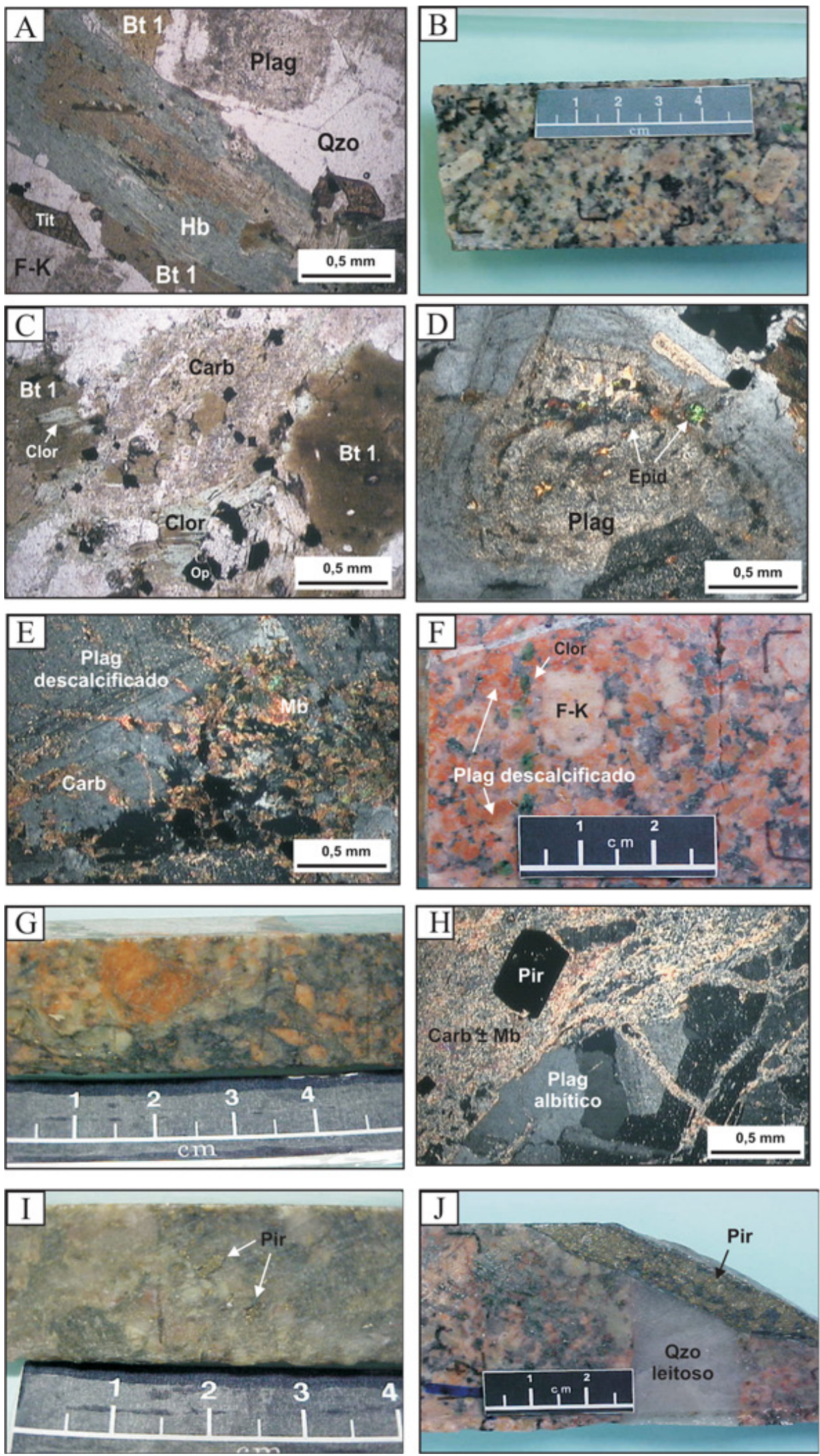

Figura 3 - Aspectos macro e microscópicos das rochas dos testemunhos de sondagem da área mineralizada do GSJJ: (A) Associação mineralógica magmática; (B) Granito hospedeiro da mineralização de ouro; (C) e (D) Associação pós-magmática precoce; Associação mineralógica (E) e rocha (F) resultantes da alteração propilítica; Rocha brechada e mineralizada $(G)$ e associação mineralógica $(H)$ típicas do estágio de alteração filica; Rochas hidrotermalizadas, contendo pirita aurifera disseminada (I) e em veio (J). Fotomicrografias sob nicóis cruzados, exceto em (A); Qzo: quartzo; Plag: plagioclásio; Bt: biotita; Hb: hornblenda; F-K: feldspato potássico; Tit: titanita; Op: opacos; Epid: epidoto; Clor: clorita; Carb: carbonato; Mb: mica branca; Pir: pirita. 
(Fig. 3A). Essa associação seria a que mais se aproxima daquela formada em condições magmáticas. Ela pode mostrar-se parcialmente alterada, com substituição de anfibólio e biotita 1 por clorita e óxidos de $\mathrm{Fe}$ e Ti, bem como saussuritização moderada do plagioclásio e presença de epidoto da variedade pistacita. Essas transformações, embora se dêem no estágio subsolidus, não parecem ser representativas dos processos hidrotermais mineralizantes. Transformações similares são observadas igualmente nas fácies portadoras de anfibólio do GSJA em pontos distantes da área mineralizada. A rocha da associação 1 corresponde macroscopicamente ao granito cinza a cinza rosado (Fig. 3B).

Associação 2 (estágio de alteração pós-magmática precoce) $\mathrm{O}$ anfibólio ígneo encontra-se inteiramente pseudomorfisado e substituído por clorita + carbonatos + óxidos de $\mathrm{Fe}$ e Ti e titanita \pm biotita \pm epidoto. A biotita 1 acha-se parcialmente cloritizada, mas ainda está presente na rocha (Fig. 3C). O plagioclásio preserva sua textura, mas a saussuritização é mais intensa e generalizada, mascarando as maclas e o zoneamento dos cristais (Fig. 3D). A titanita e os opacos primários encontram-se ainda preservados. O granito assume coloração rosada.

Associação 3 (estágio de alteração propilítica) Nestas rochas, além da substituição total do anfibólio, ocorre a alteração da biotita1 para clorita. Ambos minerais são pseudomorfisados inteiramente e a clorita, acompanhada por quantidades variáveis porém não muito expressivas de carbonatos e micas brancas, passa a ser o principal mineral ferromagnesiano. $O$ plagioclásio sofre alteração intensa, mostrando-se sempre descalcificado e substituído por micas brancas e carbonatos (Fig. 3E), assumindo uma coloração avermelhada muito característica que é responsável pela cor vermelha das rochas desse estágio (Fig. 3F). A titanita, bem como magnetita e ilmenita, mostram evidências de substituição por minerais opacos e/ou corrosão. Dois subtipos foram distinguidos: o subtipo 3B é o mais característico, tendo a clorita como fase hidrotermal mais típica. O subtipo 3A, além de apresentar menores conteúdos de clorita, difere do anterior pela ocorrência de uma biotita de granulação fina, marrom esverdeada (biotita 2), que ocorre em agregados (patches) ou preenchendo vênulas com micas brancas e carbonatos. Este subtipo representaria a superposição do evento de alteração fílica na assembléia formada no estágio de alteração propilítica precursor.

Associação 4 (estágio de alteração fílica) Essa associação é caracterizada pela presença de elevados conteúdos modais de micas brancas e carbonatos, bem como de pirita. Em amostra de mão, essas rochas assumem colorações rosa esverdeada ou verde rosada e associam-se com as principais zonas mineralizadas em sulfetos (Fig. 3G). Nesta associação, o plagioclásio não mostra zoneamento e geralmente encontra-se impregnado por micas brancas e carbonatos, mas tem aspecto relativamente límpido e maclas nítidas, sendo interpretado como um plagioclásio albítico resultante do processo de descalcificação e reor- ganização do plagioclásio original (Fig. 3H). Ele difere inteiramente do plagioclásio ígneo, não se confunde com o plagioclásio saussuritizado dominante nas associações 2 e 3 e tampouco é resultante de um processo de albitização da rocha. Em muitas amostras, os feldspatos potássicos também foram amplamente substituídos por micas brancas e carbonatos, sendo notável a redução de seu conteúdo modal (Tab. 2). O epidoto é inteiramente ausente nestas rochas, mostrando claramente que ele foi desestabilizado pelos processos hidrotermais de baixa temperatura. Isso permite distinguir muitas vezes os processos hidrotermais mineralizantes das transformações subsolidus que são observadas tanto no GSJJ mais preservado, quanto no GSJA. Há amostras do furo 9 que apresentam veios de epidoto e enriquecimento neste mineral, mas sem nenhuma evidência de mineralização associada. O subtipo 4 , contendo micas brancas, carbonatos e pirita, é dominante nesta associação. O subtipo 4B, relativamente enriquecido em clorita, representa remanescentes da assembléia formada no estágio de alteração propilítica precursor. Já o subtipo 4A contém proporções expressivas de biotita verde clara, de granulação muito fina (biotita 3), seguidamente encontrada em associação com micas brancas e carbonatos em patches ou em vênulas.

Composições Modais Os dados fornecidos na tabela 2 permitem uma visão quantitativa das variações mineralógicas presentes nas rochas da área mineralizada em função das transformações hidrotermais associadas ao processo mineralizante. As amostras consideradas menos intensamente transformadas dos furos 4,7 e 9, correspondentes àquelas das associações 1,2 e 3, onde se estima que as proporções modais de quartzo e feldspatos não foram significativamente afetadas pelo hidrotermalismo, foram plotadas nos diagramas Q-A-P e Q-A+P-M para comparação com as rochas do GSJA (Fig. 4). Constata-se que as amostras da área mineralizada se superpõem com aquelas das fácies análogas do GSJA, mostrando que não existem diferenças expressivas entre as amostras de subsuperfície do GSJJ e as últimas, em termos dos seus minerais essenciais. A mesma similaridade se observa em termos dos demais constituintes minerais e das texturas macro e microscópicas indicando que o granito da área mineralizada é petrograficamente muito similar à fácies anfibóliobiotita-monzogranito dominante no GSJA.

Mineralização A pirita é o sulfeto predominante na zona mineralizada, sendo acompanhada por calcopirita , esfalerita e, muito raramente, galena e molibdenita. Os sulfetos ocorrem preenchendo fraturas (1-20 mm de espessura), seguidamente associados com quartzo, clorita e carbonatos, ou então disseminados na rocha hospedeira (Fig. 3I). Localmente, vênulas $(1 \mathrm{~cm})$ de pirita cortam vênulas $(2 \mathrm{~cm})$ de quartzo leitoso (Fig. 3J). Nas zonas de maior deformação rúptil, observa-se uma venulação mais adensada, similar a stockworks, com intensa sulfetação associada. O ouro associa-se com a pirita, ocorrendo incluso ou em fraturas na mesma. Ele 
Tabela 2 - Composições modais de amostras dos furos de sondagem do Granito São Jorge Jovem.

\begin{tabular}{|c|c|c|c|c|c|c|c|c|c|c|c|c|c|c|c|c|c|}
\hline Furo & & & & & -02 & & & & & & & & $\mathrm{FSJ}-04$ & & & & \\
\hline Amostra & $02 / 5$ & $02 / 14$ & $02 / 19$ & $02 / 22$ & $02 / 24$ & $2 / 26$ & $02 / 31$ & $02 / 39$ & $04 / 2$ & $04 / 4$ & $04 / 7$ & $04 / 11$ & $04 / 14$ & $04 / 19$ & $4 / 28$ & $04 / 29$ & $04 / 37$ \\
\hline Associação & $3 \mathrm{~A}$ & 4 & $3 \mathrm{~B}-4$ & $4 \mathrm{~A}$ & $4 A-4 B$ & $3 B-4 B$ & $4 \mathrm{~B}$ & 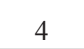 & $3 \mathrm{~A}$ & 4 & 4 & 3B & $4 \mathrm{~A}$ & 2 & $4 \mathrm{~A}$ & 1 & $3 \mathrm{~B}$ \\
\hline Quartzo & 90 & 30,00 & 28,80 & 47,80 & 29,80 & 20,60 & 30,70 & 30,20 & 2,90 & 30,40 & 48,60 & 24,80 & 25,10 & 18,20 & 8,10 & 20,30 & 19,50 \\
\hline Plagioclásio & 30 & 31,40 & 39,20 & 26,00 & 23,80 & 24,30 & 36,80 & 33,70 & 32,90 & 19,90 & 0,10 & 40,10 & 34,90 & 29,40 & 31,10 & 40,80 & 52,80 \\
\hline K-feldspato & 18,40 & 12,30 & 13,10 & 0,30 & 4,00 & 35,40 & 10,80 & 21,70 & 16,80 & 17,60 & 0,10 & 20,80 & 24,90 & 44,00 & 23,20 & 23,10 & 11,90 \\
\hline Anfibólio & $\mathrm{x}$ & $\mathrm{x}$ & $\mathrm{x}$ & $\mathrm{x}$ & $\mathrm{x}$ & $\mathrm{x}$ & $\mathrm{x}$ & $\mathrm{x}$ & $\operatorname{Tr}$ & $\mathrm{x}$ & $\mathrm{x}$ & $\mathrm{x}$ & $\mathrm{x}$ & $\mathrm{x}$ & $\mathrm{x}$ & 1,20 & $\mathrm{x}$ \\
\hline Biotita 1 & $9,80^{1}$ & $\mathrm{x}$ & $\mathrm{x}$ & $\mathrm{x}$ & $\mathrm{x}$ & $\mathrm{x}$ & $\mathrm{x}$ & $\mathrm{y}$ & 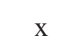 & 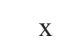 & $\mathrm{x}$ & $\mathrm{x}$ & 0,90 & 3,30 & 1,70 & 3,30 & $\mathrm{x}$ \\
\hline Biotita 2 & $\mathrm{x}$ & $\mathrm{x}$ & $\mathrm{x}$ & $\mathrm{x}$ & $\mathrm{x}$ & $\mathrm{x}$ & $\mathrm{x}$ & $\mathrm{x}$ & - & $\mathrm{x}$ & $\mathrm{x}$ & $\mathrm{x}$ & 3,20 & 0,30 & 1,30 & 0,30 & $\mathrm{x}$ \\
\hline Bio & $\mathrm{x}$ & $\mathrm{x}$ & $\mathrm{x}$ & & 3,60 & $\mathrm{x}$ & $\mathrm{x}$ & $\mathrm{x}$ & 1,90 & 0,20 & $\mathrm{x}$ & $\mathrm{x}$ & $\mathrm{x}$ & 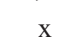 & $\mathrm{x}$ & $\mathrm{x}$ & $\mathrm{x}$ \\
\hline Titanita & 0,60 & 0,60 & $\mathrm{x}$ & 0,20 & $\mathrm{x}$ & 0,20 & $\mathrm{x}$ & 0,30 & $\mathrm{y}$ & $\mathrm{y}$ & $\mathrm{x}$ & $\mathrm{x}$ & $\mathrm{x}$ & $\mathrm{x}$ & $\mathrm{x}$ & $\mathrm{x}$ & $\mathrm{x}$ \\
\hline & 1,60 & & 1,40 & & & & 0,50 & & 0,70 & 0,30 & 0,10 & 0,80 & 0,30 & 0,60 & 0,20 & 0,40 & 1,30 \\
\hline D. & 0,30 & 0,10 & 0,60 & 0 & 0 & 0 & 2,50 & $\mathrm{x}$ & 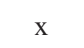 & 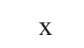 & $\mathrm{x}$ & 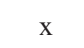 & $\mathrm{x}$ & 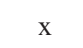 & 9,80 & $\mathrm{x}$ & $\mathrm{x}$ \\
\hline & 2,70 & 1,30 & 5,90 & 0,20 & & & $J, 10$ & $\mathrm{x}$ & 0,30 & 0,20 & $\mathrm{x}$ & 5,70 & $\mathrm{x}$ & 0,30 & 0,30 & 1,70 & 8,80 \\
\hline Carbonat & 6,20 & 13,80 & 6,00 & 4,20 & 10,90 & 6,80 & 7,40 & 7,60 & 14,70 & 12,70 & 4,50 & 1,20 & 5,70 & 1,80 & 0,90 & 0,30 & 4,00 \\
\hline Epidoto & $\operatorname{Tr}$ & $\mathrm{x}$ & $\mathrm{x}$ & $\mathrm{x}$ & $\mathrm{x}$ & $\mathrm{x}$ & $\mathrm{x}$ & $\mathrm{x}$ & $\mathrm{x}$ & $\mathrm{x}$ & $\mathrm{x}$ & $\mathrm{x}$ & $\mathrm{x}$ & $\mathrm{x}$ & $\mathrm{x}$ & $\operatorname{Tr}$ & $\mathrm{x}$ \\
\hline & $\mathrm{x}$ & 9,50 & 4,70 & 15,30 & 24,0 & & 7,30 & & 9,00 & 18,30 & 41,60 & 5,90 & 3,90 & 1,50 & 13,10 & 0,80 & 0,20 \\
\hline Acessórios & 0,20 & 0,30 & 0,30 & 0,30 & 0,40 & 0,30 & 0,30 & 0,50 & 0,60 & 0,30 & 0,80 & 0,60 & 1,00 & 0,60 & 0,30 & 0,50 & 1,20 \\
\hline & 78,60 & $13, / 0$ & & 14,10 & & & 18,30 & & 12,00 & 67,90 & 48,80 & 85,70 & 84,90 & 91,60 & 72,40 & 84,20 & 84,20 \\
\hline Máficos & 21,40 & 26,30 & 18,90 & 25,90 & 42,40 & 19,70 & 21,70 & 14,40 & 27,20 & 32,00 & 47,00 & 14,20 & 15,00 & 8,40 & 27,60 & 8,50 & 15,50 \\
\hline $\mathrm{FK}+\mathrm{Pl}$ & 59,70 & 43,70 & 52,30 & 26,30 & 27,80 & 59,70 & 47,60 & 55,40 & 49,70 & 37,50 & 0,20 & 60,90 & 59,80 & 73,40 & 54,30 & 63,90 & 64,70 \\
\hline pointus & 000 & 000 & 000 & 2000 & 000 & 2000 & 200 & 2 & 1700 & 17 & 1700 & 1700 & 1700 & 1700 & 1700 & 1700 & 1700 \\
\hline
\end{tabular}

\begin{tabular}{|c|c|c|c|c|c|c|c|c|c|c|c|c|c|c|c|c|}
\hline \multirow{2}{*}{$\begin{array}{l}\text { Furo } \\
\text { Amostra }\end{array}$} & \multicolumn{7}{|c|}{ FSJ -06} & \multicolumn{6}{|c|}{ FSJ -07} & \multicolumn{3}{|c|}{$\mathrm{FSJ}-09$} \\
\hline & $06 / 1$ & $06 / 9$ & $06 / 15$ & $06 / 19$ & $06 / 21$ & $06 / 25$ & $06 / 34$ & $07 / 3$ & $07 / 6$ & $07 / 8$ & $07 / 21$ & $07 / 28$ & $07 / 50$ & $09 / 10$ & $09 / 14$ & $09 / 16$ \\
\hline Associação & $3 \mathrm{~B}$ & $4 \mathrm{~A}$ & 4 & 4 & $4-4 \mathrm{~A}$ & $3 \mathrm{~B}$ & 2 & 1 & $3 \mathrm{~B}$ & $3 \mathrm{~B}$ & $4 \mathrm{~B}$ & aplito & $3 \mathrm{~B}$ & 1 & $4 \mathrm{~B}$ & $3 B+E p$ \\
\hline Quartzo & 2,77 & 24,05 & 23,91 & 28,16 & 17,22 & 18,25 & 23,28 & 20,40 & 24,30 & 15,60 & 16,30 & 29,40 & 19,60 & 16,93 & 17,88 & 17,59 \\
\hline Plagioclásio & 38,76 & 42,47 & 48,72 & 44,66 & 29,59 & 42,34 & 34,38 & 38,60 & 36,60 & 36,60 & 26,30 & 40,80 & 50,50 & 38,43 & 58,14 & 47,54 \\
\hline K-feldspato & 42,92 & 12,93 & 6,26 & 9,73 & 11,57 & 30,94 & 28,52 & 29,00 & 28,10 & 33,10 & 24,10 & 26,10 & 21,90 & 35,43 & 13,94 & 22,65 \\
\hline Anfibólio & $\mathrm{x}$ & $\mathrm{x}$ & $\mathrm{x}$ & $\mathrm{x}$ & $\mathrm{x}$ & $\mathrm{x}$ & $\mathrm{x}$ & 4,00 & $\mathrm{x}$ & $\mathrm{x}$ & $\mathrm{x}$ & $\mathrm{x}$ & 0,80 & 3,40 & $\mathrm{x}$ & $\mathrm{x}$ \\
\hline Biotita 1 & $\mathrm{x}$ & $\mathrm{x}$ & $\mathrm{x}$ & $\mathrm{x}$ & $\mathrm{x}$ & $\mathrm{x}$ & 3,70 & 6,00 & $\operatorname{Tr}$ & $\mathrm{x}$ & $\mathrm{x}$ & $\mathrm{x}$ & $\mathrm{x}$ & 3,48 & $\mathrm{x}$ & $\mathrm{x}$ \\
\hline Biotita 2 & $\mathrm{x}$ & $\mathrm{x}$ & $\mathrm{x}$ & $\mathrm{x}$ & $\mathrm{x}$ & 0,60 & $\mathrm{x}$ & $\mathrm{x}$ & $\mathrm{x}$ & $\mathrm{x}$ & $\mathrm{x}$ & $\mathrm{x}$ & $\mathrm{x}$ & $\mathrm{x}$ & $\mathrm{x}$ & $\mathrm{x}$ \\
\hline Biotita 3 & $\mathrm{x}$ & 1,05 & 0,66 & 0,45 & 3,84 & $\mathrm{x}$ & $\mathrm{x}$ & $\mathrm{x}$ & $x$ & $\mathrm{x}$ & $\mathrm{x}$ & $\mathrm{x}$ & $x$ & $x$ & $\mathrm{x}$ & $x$ \\
\hline Titanita & $\mathrm{x}$ & $\mathrm{x}$ & $\mathrm{x}$ & $\mathrm{x}$ & $\mathrm{x}$ & $\mathrm{x}$ & 0,94 & 0,50 & 1,20 & 1,00 & 0,10 & $\operatorname{Tr}$ & 1,00 & 0,50 & 0,12 & 0,12 \\
\hline Opacos & 1,10 & 0,35 & $\mathrm{x}$ & 0,49 & 0,88 & 0,64 & 0,61 & 0,90 & 0,80 & 2,00 & 7,00 & 0,30 & 0,40 & 0,80 & 0,31 & 0,11 \\
\hline Pirita (?) & $\mathrm{x}$ & $\mathrm{x}$ & 5,40 & $\mathrm{x}$ & $\mathrm{x}$ & $\mathrm{x}$ & $\mathrm{x}$ & $\mathrm{x}$ & $\mathrm{x}$ & $\mathrm{x}$ & $\mathrm{x}$ & $\mathrm{x}$ & $\mathrm{x}$ & $\mathrm{x}$ & $\mathrm{x}$ & $\mathrm{x}$ \\
\hline Clorita & 9,65 & $\mathrm{x}$ & $\mathrm{x}$ & 0,09 & $\mathrm{x}$ & 4,64 & 6,17 & 0,40 & 5,70 & 2,70 & 3,40 & 0,40 & 3,60 & 1,02 & 2,49 & 4,94 \\
\hline Carbonato & 2,49 & 4,79 & 6,51 & 8,59 & 9,44 & 0,23 & 2,16 & $\mathrm{x}$ & 1,40 & 9,60 & 2,70 & 0,80 & 0,60 & $\mathrm{x}$ & 5,43 & 3,05 \\
\hline Epidoto & $\mathrm{x}$ & $\mathrm{x}$ & $\mathrm{x}$ & $\mathrm{x}$ & $\mathrm{x}$ & $\mathrm{x}$ & $\mathrm{x}$ & 0,10 & $\mathrm{x}$ & $\mathrm{x}$ & $\mathrm{x}$ & $\mathrm{x}$ & 1,20 & $\mathrm{x}$ & $\mathrm{x}$ & $\operatorname{Tr}$ \\
\hline Mica branca & 2,17 & 14,17 & 8,21 & 7,05 & 26,91 & 1,05 & $\mathrm{x}$ & $\mathrm{x}$ & $\mathrm{x}$ & $\mathrm{x}$ & 19,20 & 1,60 & $\mathrm{x}$ & $\operatorname{Tr}$ & 1,68 & $\mathrm{x}$ \\
\hline Acessórios & 0,13 & 0,20 & 0,33 & 0,76 & 0,51 & 1,29 & 0,24 & 0,20 & $\mathrm{x}$ & $\operatorname{Tr}$ & $\operatorname{Tr}$ & 0,30 & 0,10 & $\operatorname{Tr}$ & $\operatorname{Tr}$ & $\operatorname{Tr}$ \\
\hline Félsicos & 84,45 & 79,45 & 78,89 & 82,55 & 58,38 & 91,53 & 86,18 & 88,00 & 89,00 & 85,30 & 66,70 & 96,30 & 92,00 & 90,79 & 89,96 & 87,78 \\
\hline Máficos & 15,54 & 20,56 & 21,11 & 17,43 & 41,58 & 8,45 & 13,82 & 12,10 & 9,10 & 15,30 & 32,40 & 3,40 & 6,90 & 2,32 & 10,03 & 8,22 \\
\hline $\mathrm{FK}+\mathrm{Pl}$ & 81,68 & 55,40 & 54,98 & 54,39 & 41,16 & 62,90 & 62,90 & 67,60 & 64,70 & 69,70 & 50,40 & 66,90 & 72,40 & 73,86 & 72,08 & 70,19 \\
\hline $\mathrm{N}^{o}$ pontos & 2166 & 2000 & 2420 & 2230 & 2375 & 2175 & 2135 & 1700 & 1700 & 1700 & 1500 & 1500 & 1500 & 1700 & 1700 & 1700 \\
\hline
\end{tabular}

${ }^{1}=$ Inclui proporção subordinada de biotita 2

foi identificado com microscópio ótico em luz refletida e confirmado em microscopia eletrônica de varredura.

QUÍMICA MINERAL As análises das variedades texturais de clorita, micas brancas e biotita presentes na zona mineralizada foram obtidas no Laboratório de Microssonda Eletrônica do Instituto de Geociências da UFRGS por intermédio de uma microssonda CAMECA SX-50, sob as seguintes condições operacionais: tensão de aceleração de $15 \mathrm{kv}$; corrente elétrica de $10 \mathrm{nA}$; tem- 


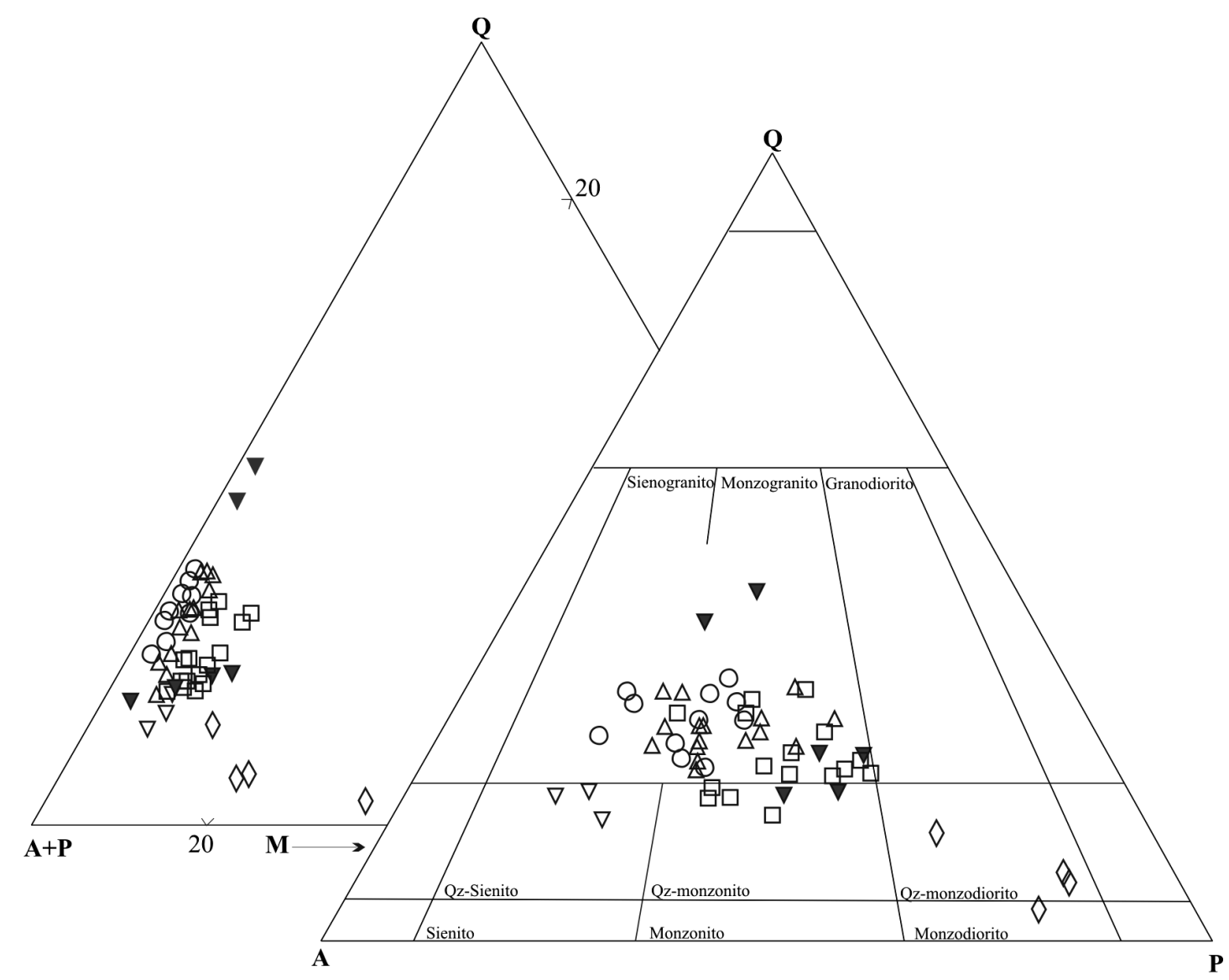

$\begin{array}{ll}\text { Granito São Jorge Antigo } & \text { Granito São Jorge Jovem } \\ \text { O BLMZG/SG - centro } & \text { ₹ ABMZG a ABQM } \\ \triangle \text { BLMZG/SG - sul } & \\ \nabla \text { ABQS } & \\ \square \text { ABMZG a ABQM } & \\ \diamond \text { BAMD a BAQMD } & \end{array}$

Figura 4 - Diagramas QAP e Q-(A+P)-M (Streckeisen 1976) mostrando a distribuição das amostras dos granitos São Jorge Antigo e São Jorge Jovem (modificado de Lamarão 2001). Siglas das fácies como na figura 1.

pos de contagem de 30s para F, Mg, Al, Na, Si e Sr e de 20s para $\mathrm{Cl}, \mathrm{K}, \mathrm{Ca}, \mathrm{Mn}$, Ti e Fe; tamanhos do feixe de elétrons de 1 micron para micas e clorita. Composições dos anfibólios da zona mineralizada do GSJJ foram apresentadas em Lamarão \& Dall'Agnol (2004) e seus resultados serão utilizados nas discussões seguintes. A fórmula estrutural da clorita foi calculada com base em 28 átomos de oxigênio, enquanto as das micas brancas e biotita foram calculadas com base em 22 átomos de oxigênio. Análises representativas da clorita, micas brancas e biotita da zona mineralizada constam, respectivamente, das tabelas 3, 4 e 5 . As amostras selecionadas para análises são quase todas provenientes dos furos 2 e 4 , ambos intensamente hidrotermalizados e mineralizados, sendo exceção a amostra F9/10, representativa do monzogranito menos intensamente transformado.

Clorita Tendo em vista a importância da clorita nos processos hidrotermais que afetaram as rochas mineralizadas e a possibilidade de seu uso como geotermômetro (Cathelineau 1988), procurou-se determinar, em amostras representativas das diversas associações hidrotermais, as composições das três variedades texturais de clorita identificadas: 1) presente nos pseudomorfos de anfibólio; 2) em veios; 3) proveniente da substituição da biotita.

As três variedades de clorita apresentam composições bastante semelhantes, independentemente da associação hidrotermal em que se encontram (Tab. 3). Ela é rica em $\mathrm{Mg}$ e é classificada como clinocloro (Bailey, 1980). O diagrama $\mathrm{Fe} /\left(\mathrm{Fe}+\mathrm{Mg}\right.$ ) vs. ${ }^{\mathrm{IV}} \mathrm{Al}$ (Fig. 5a) mostra que a maioria dos cristais de clorita possui razões $\mathrm{Fe} /(\mathrm{Fe}+\mathrm{Mg})$ entre 0,30 e 0,35 , alcançando valores um pouco mais elevados, em torno de 0,40 , na amostra F2/26. Ele revela também variações significativas nos conteúdos de ${ }^{\mathrm{IV}} \mathrm{Al}$, refletindo variações na temperatura de formação da clorita (Cathelineau 1988; Zhang \& 
Tabela 3 - Análises de microssonda eletrônica representativas de clorita dos testemunhos de sondagem do depósito São Jorge.

\begin{tabular}{|c|c|c|c|c|c|c|c|c|c|c|c|c|c|c|c|c|c|}
\hline (1) & & $2 / 5$ & & & F2/19 & & & & $2 / 26$ & & $4 / 4$ & & & 4/11 & & & 10 \\
\hline $\mathrm{N}^{\circ}$ análise & P17 & S4P15 & P27 & S11P32 & S3P28 & S11P33 & S7P51 & S4P83 & S4P85 & S1P166 & S1P168 & P187 & 85 & S5P184 & 39 & 9 & S5P75 \\
\hline Sineral & (Bt) & $\mathrm{Cl}(\mathrm{Bt})$ & l(v) & $\mathrm{Cl}(\mathrm{H}$ & $\mathrm{Cl}(\mathrm{v})$ & $\mathrm{Cl}(\mathrm{Hb})$ & $\mathrm{Cl}(\mathrm{Bt})$ & $\mathrm{Cl}(\mathrm{v})$ & $\mathrm{Cl}(\mathrm{Bt})$ & $\mathrm{Cl}(\mathrm{Bt})$ & $\mathrm{Cl}(\mathrm{Bt})$ & $\mathrm{Cl}(\mathrm{Bt})$ & t) & $\mathrm{Cl}(\mathrm{Bt})$ & $\mathrm{Cl}(\mathrm{Bt})$ & 3t) & $1(\mathrm{Bt})$ \\
\hline 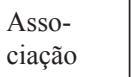 & & $F$ & & & 3 & & & 3 & - & & 4 & & & $3 \mathrm{~B}$ & & & 1 \\
\hline $\mathrm{iO}_{2}$ &, 344 & 28,069 & 26,992 & 27,106 & 27,233 & 27,295 & 28,954 & 26,604 & 27,537 & 28,177 & 28,616 & 29,079 & 29,520 & 29,740 & 30,277 & 29,761 & 28,054 \\
\hline 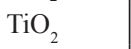 & 0,059 & 0,000 & 0,042 & 0,136 & 0,000 & 0,153 & 0,025 & 0,126 & 0,059 & 0,051 & 0,034 & 0,068 & & 0,102 &, 145 &, 128 & 0,000 \\
\hline${ }_{2} \mathrm{O}_{3}$ & 19,896 & 19,674 & 20,804 & 20,240 & 20,998 & 19,661 & 18,305 & 19,937 & 19,215 & 18,832 & 18,796 & 18,395 & 18,137 & 17,417 & &, 532 & 17,636 \\
\hline$x=$ & 20,627 & 19,483 &, 064 & 19,903 & 20,507 & 20,323 & 21,586 & 17,727 & 18,767 & 20,859 & 20,941 & 21,343 & 20,943 & & &, 124 & 19,866 \\
\hline & 007 & 0011 & 021 & (112 & & (101 & 0,071 & 0,012 & 0,000 & 0,018 & & & & & & & 0,051 \\
\hline $\operatorname{Mn}$ & 0,366 & 0,294 & 0,426 & 0,356 & 62 & 0 & 361 & 0,993 & 0,588 & 0,349 & 48 & & & & & 30 & 0,507 \\
\hline & 18,894 & 18,465 & 698 & 19,187 & & & 17,865 & 21,896 & 21,347 & 286 & & & & & & 74 & 20,505 \\
\hline $\mathrm{Na}_{2}$ & 00 & & 0 & & & & 00 & 0,000 & 0,000 & 0,000 & & & & & & 00 & 0,000 \\
\hline & 110 & & 052 & & & & 29 & 0,118 & 0,076 & 0,000 & & & & & & 35 & 0,018 \\
\hline 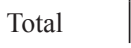 & 87,306 & 86 & 87,112 & 87 & 88,221 & 85 & 87 & 87,416 & 87,592 & 87 & 92 & 8 & 42 & & & & 86,631 \\
\hline \multicolumn{18}{|c|}{ trutural calculada na base de 28 átomos de oxigênio } \\
\hline $\mathrm{Si}$ & 590 & 5,781 & 521 & 5560 & 5504 & 5640 & 5,878 & 3 & ,687 & 5,744 & & & & & & 39 & 5,834 \\
\hline & 10 & & & & & & & 2,457 & & 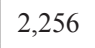 & & & & & & & 2,166 \\
\hline in & 000 & 8,000 & 8,000 & 8,00 & 8,0 & 8,000 & 8,000 & 8,000 & 8,000 & 8,000 & 8,000 & 000 & 8 & 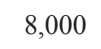 & 8,000 & 00 & 8,000 \\
\hline & & & & & & & & & & & & & & & & & 157 \\
\hline . & 29 & & & & & & & & 36 & & & & & & & & 3,565 \\
\hline $\mathrm{Mg}$ & 301 & 5,997 & 9 & 6,104 & 6,194 & 6 & 50 & 5,520 & 5,792 & 5 & 8 & 443 & & & 4 & 06 & 6,174 \\
\hline & & & & & & & & & & & & & & & & & 0,089 \\
\hline Ti & 09 & 0 & 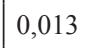 & 0,021 & & 3 & 4 & 019 & 9 & 8 & 5 & 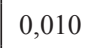 & & & 2 & 19 & 0,000 \\
\hline & & & & & & & & & & & & & & & & & 0,011 \\
\hline $\mathrm{Na}$ & 000 & 0,000 & 0,000 & & & & & 000 & 0,000 & 0 & & & & & & 00 & 0,000 \\
\hline K & 0,028 & & 0,04 & & & & & 0,031 & 0,020 & 0,000 & & & & & & 35 & 0,011 \\
\hline & 2,018 & 11,872 & 1,971 & 11,969 & 002 & 11 , & 11,931 & 12,004 & 11,975 & 11,985 & 11,882 & 11,926 & 89 & 04 & 51 & 11,862 & 12,009 \\
\hline & 018 & 1 & & 19 & & 19 & 19 & 2 & 19 & 35 & 19 & 6 & 39 & & & & 2 \\
\hline 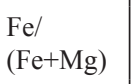 & & & & & & & & & & & & & & & & 32 & 0,37 \\
\hline & & & & & & & & 4, & & & & & & & & & 4,32 \\
\hline$\left({ }^{\circ} \mathrm{C}\right)$ & 326 & 295 & 337 & 331 & 341 & 318 & & 334 & 310 & 302 & 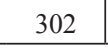 & 2 & 01 & 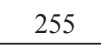 & 241 & 54 & 287 \\
\hline
\end{tabular}

$\mathrm{Cl}=$ Clorita; $\mathrm{Bt}=$ clorita proveniente da substituição da biotita; $\mathrm{Hb}=$ clorita presente nos pseudomorfos de anfibólio; $\mathrm{v}=$ clorita preenchendo veio.

Fyfe 1995). Tendo em vista o caráter acentuadamente magnesiano das composições obtidas, empregou-se o geotermômetro de Cathelineau (1988). Embora, a primeira vista, não haja uma relação constante entre o tipo textural e as temperaturas obtidas (Tab. 3), percebe-se uma tendência para temperaturas decrescentes de formação para a clorita presente nos veios, à associada aos pseudomorfos de anfibólio e, finalmente, àquela proveniente da biotita. Isso é melhor evidenciado no caso da clorita da amostra F2/19 (Fig. 5b) e menos claramente no caso daquelas provenientes das diversas amostras do furo 4 (Fig. $5 \mathrm{c}$ ). Porém sempre há superposições entre os intervalos de temperatura sugeridos $\left(300 \pm 40^{\circ} \mathrm{C}\right)$ para os diferentes tipos texturais. A interpretação mais plausível para as temperaturas indicadas pelo geotermômetro empregado é que as diferentes variedades texturais de clorita formaram-se em intervalos de tempe- ratura próximos; a implicação disso é que a clorita das associações hidrotermais 3 e 4 teria se formado muito provavelmente em intervalos de temperatura próximos e, possivelmente, parcialmente superpostos.

Micas Brancas Tal como no caso da clorita, procurou-se analisar em diversas amostras dos furos 2 e 4, os diferentes tipos texturais de micas brancas, incluindo: 1) agregados de mica muito fina $(<0,1 \mathrm{~mm}) ; 2)$ cristais bem desenvolvidos $>0,5 \mathrm{~mm}) ; 3$ ) cristais de hábito radial; 4) lamelas preenchendo veios. Excetuando a amostra F4/11 (Tab. 4), as demais amostras possuem micas brancas com deficiência intercamada $(0,6<x+y$ $<0,85)$, cujos demais parâmetros químicos $\left(\mathrm{Mg}>\mathrm{Fe}^{\mathrm{II}}\right.$; $\left.{ }^{\mathrm{IV}} \mathrm{Al}>{ }^{\mathrm{IV}} \mathrm{Fe}^{\mathrm{III}} ;{ }^{\mathrm{VI}} \mathrm{Al} /\left({ }^{\mathrm{VI}} \mathrm{Al}+{ }^{\mathrm{VI}} \mathrm{Fe}^{\mathrm{III}}\right)>0,6\right)$ permitem classificá-las como illita (Rieder et al. 1998). As composições obtidas são muito similares, não cabendo uma discussão 
Tabela 4 - Análises de microssonda eletrônica representativas de micas brancas dos testemunhos de sondagem do depósito São Jorge.

\begin{tabular}{|c|c|c|c|c|c|c|c|c|c|c|c|c|c|c|c|c|c|c|}
\hline \multirow{3}{*}{$\begin{array}{l}\text { Amostra } \\
\mathrm{N}^{\circ} \\
\text { análise } \\
\text { Mineral }\end{array}$} & \multicolumn{3}{|c|}{$\mathrm{F} 2 / 19$} & \multicolumn{3}{|c|}{$\mathrm{F} 2 / 22$} & \multicolumn{4}{|c|}{$\mathrm{F} 2 / 24$} & \multicolumn{3}{|c|}{$\mathrm{F} 4 / 7$} & \multicolumn{3}{|c|}{$\mathrm{F} 4 / 4$} & \multicolumn{2}{|c|}{ F4/11 } \\
\hline & $\mathrm{S} 15 \mathrm{P} 40$ & S6P43 & S2P37 & $\mathrm{S} 2 \mathrm{P} 53$ & S2P54 & S4P69 & S9P110 & S6P104 & S11P100 & S1P98 & S5P158 & S5P159 & S5P154 & S2P170 & S5P174 & S5P173 & S9P193 & S9P194 \\
\hline & $\mathrm{Mb}$ & $\mathrm{Mb}$ & $\mathrm{Mb}(\mathrm{v})$ & $\mathrm{Mb}$ & $\mathrm{Mb}$ & $\mathrm{Mb}$ & $\mathrm{Mb}(\mathrm{rd})$ & l) $\mathrm{Mb}(\mathrm{rd})$ & $\mathrm{Mb}(\mathrm{v})$ & $\mathrm{Mb}$ & $\mathrm{Mb}$ & $\mathrm{Mb}$ & $\mathrm{Mb}$ & $\mathrm{Mb}(\mathrm{rd})$ & $\mathrm{Mb}$ & $\mathrm{Mb}$ & $\begin{array}{c}\mathrm{Mb} \\
\text { (fina) }\end{array}$ & $\begin{array}{c}\mathrm{Mb} \\
\text { (fina) }\end{array}$ \\
\hline $\begin{array}{l}\text { Asso- } \\
\text { ciação }\end{array}$ & \multicolumn{3}{|c|}{$3 \mathrm{~B}-4$} & \multicolumn{3}{|c|}{$4 \mathrm{~A}$} & \multicolumn{4}{|c|}{$4 \mathrm{~A}-4 \mathrm{~B}$} & \multicolumn{3}{|c|}{4} & \multicolumn{3}{|c|}{4} & \multicolumn{2}{|c|}{$3 \mathrm{~B}$} \\
\hline $\mathrm{SiO}_{2}$ &, 225 & 50,323 & 50,706 & 51,00 &, 32 & 612 & 50 , & 301 & 52,239 & 52,612 & 51,916 & 52,676 & 52,727 & 49,371 & 50,943 & 50,950 & 47,944 & 48,371 \\
\hline $\mathrm{TiO}_{2}$ & 0,238 & 0,388 & 0,185 & 309 & 0,459 & 0,344 & 0,292 & 0,168 & 0,221 & 0,230 & 0,382 & 0,319 & 0,177 & 0,476 & 0,195 & 0,301 & 0,000 & 0,009 \\
\hline $\mathrm{Al}_{2} \mathrm{O}_{3}$ & 29,933 & 30,235 & 29,491 & 32,164 & 30,784 & 29,793 & 31,046 & 30,201 & 29,994 & 30,361 & 31,215 & 29,623 & 31,040 & 28,938 & 30,775 & 29,829 & 33,389 & 33,367 \\
\hline $\mathrm{MgO}$ & 2,302 & 2,190 & 2,911 & 2,059 & 2,730 & 2,684 & 2,159 & 2,778 & 2,406 & 2,440 & 2,286 & 2,778 & 2,386 & 3,012 & 2,571 & 3,426 & 1,340 & 1,326 \\
\hline $\mathrm{CaO}$ & 0,002 & 0,000 & 0,038 & 105 & 0,073 & 0,050 & 1 & 0,106 & 0,0190 & 0,041 & & 0,075 & 0,015 & & 0,000 & 0,000 & 0,052 & 0,051 \\
\hline $\mathrm{InO}$ & 0,000 & 0,043 &, 017 & 23 & 0,067 & 000 & 9 & ,043 & 0,0 & 16 & 1 & ,036 & 20 & 3 & 0,001 & 39 & 0,016 & 0,046 \\
\hline $\mathrm{FeO}$ & 4,887 & 5,069 & 3,841 & 128 & 3,485 & 3,832 & 4,026 & 4,023 & 3,878 & 723 & & 3,808 & 18 & & 4,689 & 72 & 3,768 & 3,900 \\
\hline $\mathrm{Na}_{2} \mathrm{O}$ & 0,065 & 0,133 & 0,068 & 101 & 0,145 & 0,088 & 0,061 & 0,112 & 0,095 & 0,020 & 0,128 & 0,129 & 0,054 & 0,083 & 0,054 & 0,109 & 0,153 & 0,193 \\
\hline $\mathrm{K}_{2} \mathrm{O}$ & 9,667 & 9,656 & 9,145 & 596 & 7,708 & 7,782 & 8,691 & 8,213 & 8,275 & ,382 & 9,064 & 8,289 & 8,225 & 7,6 & 8,972 & 8,229 & 9,830 & 10,095 \\
\hline $\mathrm{F}$ & 0,367 & 0,525 & 0,420 & 529 & 0,320 & 0,265 & 0,000 & 0,936 & 0,000 & 000 & 0,264 & 0,000 & 79 & & 0,261 & 05 & 0,000 & 0,000 \\
\hline $\mathrm{Cl}$ & 0,002 & 0,000 & 0,008 & 016 & 0,000 & 0,039 & 26 & 0,003 & 0,007 & 31 & 00 & 0,000 & 0,003 & 2 & 0,002 & 00 & 0,008 & 0,003 \\
\hline Total & 97,687 & 98,562 & 96,832 & 97,038 & 397,094 & 96,489 & 96,754 & 97 & 97 , & 97,856 & 98,668 & 98,734 & 98 & 96,262 & 98,462 & 97,659 & 96,500 & 97,362 \\
\hline $\mathrm{O}=\mathrm{F}$ & 0,154 & 0,221 & 0,177 & 0,223 & 0,134 & 0,111 & 0,000 & 0,394 & 0,000 & 0,000 & 11 & 0,000 & 44 & 7 & 0,110 & 44 & 0,000 & 0,000 \\
\hline$=\mathrm{Cl}$ & 0,000 & 0,000 & 0,002 & 4 & 0,000 & 99 & & 00 & 0,002 & 07 & & 00 & 0 & & 0,000 & 00 & 0,002 & 0,001 \\
\hline TOTAL & 97,532 & 98,341 & 96,653 & 96,8 & 96,960 & 96,369 & 96, & & & & & 34 & & & & 15 & 96,498 & 7,361 \\
\hline \multicolumn{19}{|c|}{ Fórmula estrutural calculada na base de 22 átomos de oxigênio } \\
\hline $\mathrm{Si}$ & 6,597 & 6,569 & 6,666 & & 6,644 & 6,729 & 6,583 & 6,668 & 6,757 & 6,752 & & 6,774 & 36 & & 6,587 & 13 & 6,332 & 6,345 \\
\hline IV & 1403 & 431 & 13 & + & 1,356 & 1 & & 32 & 1 , & 48 & & 26 & 4 & & 13 & 1 & 1,668 & 1,655 \\
\hline tio $\mathrm{T}$ & 000 & 000 & 8,000 & 000 & 8,000 & 8,000 & 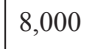 & 00 & 8,000 & 00 & 000 & 8,000 & 0 & & 8,000 & 0 & 8,000 & 8,000 \\
\hline $1^{\mathrm{VI}}$ & 3,232 & 3,222 & 3,236 & 99 & 3,341 & 08 & 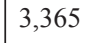 & 3 , & 3,3 & 44 & & 3,265 & 09 & & 3,278 & 76 & 3,531 & 3,504 \\
\hline in & 0,537 & 0,553 & 0,422 & 38 & 0,377 & 0,418 & 0 & 0,437 & 0,420 & 99 & 62 & 0,409 & 47 & 2 & 0,507 & 97 & 0,416 & 0,428 \\
\hline Mg & 52 & ,427 & & 8 & 0,528 & 23 & & & & 68 & & 34 & & & 0,497 & &, 264 & 0,260 \\
\hline $\mathrm{Mn}$ & 0,000 & 0,005 & 0,002 & 03 & 0,007 & 0,000 & 3 & 05 & 0, & 02 & 01 & 0,004 & 2 & 6 & 0,000 & 4 & 0,002 & 0,005 \\
\hline 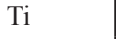 & 0,023 & 0,038 & & 0 & 0,045 & 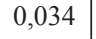 & & & & 22 & & 0, & & & 19 & &, 000 & 0,001 \\
\hline o O & 4,244 & 4,245 & 4,250 & 268 & 4,282 & 4,282 & 4,258 & 4,293 & 4,238 & 36 & 99 & 4,243 & 4,231 & 4,432 & 4,301 & 4,381 & 4,213 & 4,198 \\
\hline $\mathrm{Ca}$ & 0,000 & 0,000 & 0,003 & 15 & 0,010 & 0,007 & & 0,015 & & 06 & & 0,010 & 02 & 4 & 0,000 & 0,000 &, 007 & 0,007 \\
\hline No & 0,016 & 0,034 & 0,017 & 025 & 0,036 & 0,022 & 0016 & 0,028 & & 0,005 & 0,032 & 0,032 & 0013 & & 0,014 & 0,024 & 0,039 & 0,049 \\
\hline $\mathrm{K}$ & 1,620 & 1,608 & 1,534 & 53 & 1,273 & 1,294 & 1,449 & 1,362 & 1,365 & 1,372 & 1,480 & 1,360 & 1,340 & 1,303 & 1,480 & 1,362 & 1,656 & 1,689 \\
\hline tet- & 36 & 1,642 & & 93 & 1,319 & 1,323 & 1 & & & 83 & & 1,402 & & & 1,493 & 90 & 1,703 & 1,745 \\
\hline $\mathrm{F}$ & & 0,217 & & & 0,130 & & & & & & & 0,000 & & & 0,107 & & 0,000 & 0,000 \\
\hline $\mathrm{Cl}$ & 0,000 & 0,000 & 0,002 & 004 & 0,000 & 0,009 & 0,006 & 0,000 & 0,001 & 0,007 & 0,000 & 0,000 & 0,000 & 0,014 & 0,000 & 0,000 & 0,002 & 0,001 \\
\hline Fet & 0,54 & 0,56 & 0,42 & 0,46 & 0,42 & 0,44 & 0,51 & 45 & & & & 3 & & 52 & 0,51 & 0,43 & 0,61 & 0,62 \\
\hline Al total & 4,03 & 4,65 & 4,Jו & 4,90 & 4,70 & 4,58 & 4,10 & 4,63 & 4,31 & 4,59 & 4,71 & 4,49 & 4,67 & 4,כ & 4,69 & 4,56 & 5,20 & 5,16 \\
\hline
\end{tabular}

$\mathrm{Mb}=$ Mica branca; $\mathrm{v}=$ veio; $\mathrm{rd}=$ radial .

por tipo textural. Tal illita possui teores expressivos de $\mathrm{Mg}$ e $\mathrm{Fe}$ e suas razões $\mathrm{Fe} /(\mathrm{Fe}+\mathrm{Mg})$ variam entre $0,38 \mathrm{e}$ 0,56 . Pelos parâmetros químicos apresentados, a amostra F4/11 seria classificável como uma muscovita fengítica. Embora o diagrama $\mathrm{Al}_{t}-\mathrm{M}^{2+}$ - Si não seja estritamente aplicável às micas estudadas, pelo fato das mesmas apresentarem deficiência no sítio intercamadas, utilizou-se o mesmo para uma representação gráfica do grau de subs- tituição do $\mathrm{Al}_{t}$ por $\mathrm{Si}+\mathrm{R}^{2+}$ nas micas do depósito São Jorge (Fig. 6). Constata-se que, caso as micas estudadas pertencessem a série muscovitafengitaceladonita, elas se situariam próximo da composição das fengitas. As micas da amostra F4/11 distinguem-se das demais pelo seu relativo empobrecimento em Si e $\mathrm{R}^{2+}$ (Fig. 6b). Embora com ressalvas, devido ao fato das micas estudadas experimentalmente por Monier \& Robert (1986) não serem 
Tabela 5 - Análises de microssonda eletrônica representativas de biotita dos testemunhos de sondagem do depósito São Jorge.

\begin{tabular}{|c|c|c|c|c|c|c|c|c|c|c|c|c|c|c|c|c|c|c|}
\hline \multirow{2}{*}{$\begin{array}{l}\text { Amostra } \\
\mathrm{N}^{\circ} \\
\text { análise }\end{array}$} & \multicolumn{2}{|c|}{$\mathrm{F} 2 / 5$} & \multicolumn{2}{|c|}{$\mathrm{F} 4 / 29$} & \multicolumn{2}{|c|}{ F9/10 } & \multicolumn{4}{|c|}{$\mathrm{F} 2 / 5$} & \multicolumn{2}{|c|}{$\mathrm{F} 4 / 29$} & \multicolumn{4}{|c|}{$\mathrm{F} 2 / 22$} & \multicolumn{2}{|c|}{ F4/4 } \\
\hline & S3P20 & S3P19 & S3P112 & S3P114 & S5P72 & S5P73 & S6P11 & S6P12 & S6P9 & S6P8 & S4P142 & S4P139 & S11P61 & S13P59 & S9P67 & S11P62 & S6P178 & S5P175 \\
\hline Mineral & Bt 1 & Bt 1 & Bt 1 & Bt 1 & Bt 1 & Bt 1 & Bt 2 & Bt 2 & Bt 2 & Bt 2 & Bt 2 & Bt 2 & Bt 3 & Bt 3 & $\mathrm{Bt} 3$ & $\mathrm{Bt} 3$ & Bt 3 & Bt 3 \\
\hline $\begin{array}{l}\text { Asso- } \\
\text { ciação }\end{array}$ & \multicolumn{2}{|c|}{$3 \mathrm{~A}$} & \multicolumn{2}{|c|}{1} & \multicolumn{2}{|r|}{1} & \multicolumn{4}{|c|}{$3 \mathrm{~A}$} & \multicolumn{2}{|c|}{1} & \multicolumn{4}{|c|}{$4 \mathrm{~A}$} & \multicolumn{2}{|c|}{4} \\
\hline $\mathrm{SiO}_{2}$ & 38,197 & 38,358 & 38,143 & 38,201 & 37,313 & 37,726 & 37,560 & 38,318 & 38,697 & 38,746 & 38,978 & 39,458 & 37,960 & 38,942 & 39,244 & 39,834 & 38,349 & 40,347 \\
\hline $\mathrm{TiO}_{2}$ & 2,914 & 2,618 & 2,663 & 3,143 & 3,565 & 2,474 & 1,525 & 1,782 & 1,035 & 1,31 & 1,803 & 2,098 & 0,855 & 0,707 & 0,974 & 0,753 & 0,927 & 0,879 \\
\hline $\mathrm{Al}_{2} \mathrm{O}_{3}$ & 15,089 & 14,066 & 14,413 & 14,221 & 14,282 & 214,610 & 16,572 & 15,938 & 15,602 & 15,852 & 15,330 & 14,628 & 16,132 & 15,134 & 14,900 & 14,919 & 15,474 & 14,545 \\
\hline $\mathrm{MgO}$ & 13,105 & 14,484 & 13,800 & 13,228 & 12,440 & 13,298 & 13,772 & 13,776 & 14,308 & 14,072 & 15,025 & 14,508 & 14,347 & 14,875 & 15,189 & 15,298 & 15,966 & 15,843 \\
\hline $\mathrm{CaO}$ & 0,011 & 0,000 & 0,066 & 0,040 & 0,000 & 0,020 & 0,040 & 0,083 & 0,012 & 0,015 & 0,007 & 0,000 & 0,054 & 0,034 & 0,028 & 0,021 & 0,085 & 0,016 \\
\hline $\mathrm{MnO}$ & 0,282 & 0,203 & 0,387 & 0,394 & 0,395 & 0,407 & 0,206 & 0,197 & 0,192 & 0,159 & 0,343 & 0,306 & 0,284 & 0,292 & 0,291 & 0,300 & 0,249 & 0,246 \\
\hline $\mathrm{FeO}$ & 15,669 & 16,347 & 15,735 & 16,097 & 16,700 & 16,355 & 15,095 & 15,297 & 14,538 & 14,529 & 15,189 & 15,187 & 15,292 & 15,615 & 13,950 & 13,570 & 14,783 & 12,529 \\
\hline $\mathrm{Na}_{2} \mathrm{O}$ & 0,026 & 0,064 & 0,019 & 0,075 & 0,000 & 0,000 & 0,000 & 0,056 & 0,104 & 0,007 & 0,000 & 0,000 & 0,000 & 0,033 & 0,033 & 0,018 & 0,000 & 0,088 \\
\hline $\mathrm{K}_{2} \mathrm{O}$ & 9,788 & 10,258 & 10,281 & 10,134 & 10,287 & 10,435 & 9,877 & 10,091 & 10,200 & 9,792 & 9,929 & 10,112 & 9,807 & 10,095 & 10,381 & 9,964 & 9,167 & 10,118 \\
\hline 1 & 0,000 & 0,381 & 0,339 & 0,290 & 0,409 & 0,897 & 0,673 & 0,336 & 0,674 & 0,818 & 1,413 & 0,433 & 1,091 & 0,807 & 1,760 & 1,435 & 0,812 & 1,263 \\
\hline $\mathrm{Cl}$ & 0,027 & 0,052 & 0,017 & 0,025 & 0,015 & 0,013 & 0,033 & 0,014 & 0,052 & 0,030 & 0,000 & 0,030 & 0,018 & 0,076 & 0,044 & 0,038 & 0,058 & 0,045 \\
\hline Total & 95,107 & 96,832 & 95,864 & 95,849 & 95,407 & 96,236 & 95,354 & $+95,888$ & 95,416 & 95,331 & 98,017 & 96,759 & 95,840 & 96,611 & 96,795 & 96,150 & 95,870 & 95,920 \\
\hline $\mathrm{O}=\mathrm{F}$ & 0,000 & 0,160 & 0,143 & 0,122 & 0,172 & 0,378 & 0,283 & 0,142 & 0,284 & 0,344 & 0,595 & 0,182 & 0,459 & 0,340 & 0,741 & 0,604 & 0,342 & 0,532 \\
\hline $\mathrm{O}=\mathrm{Cl}$ & 0,006 & 0,012 & 0,004 & 0,006 & 0,003 & 0,003 & 0,007 & 0,003 & 0,012 & 0,007 & 0,000 & 0,007 & 0,004 & 0,017 & 0,010 & 0,009 & 0,013 & 0,010 \\
\hline TOTAL & 95,101 & 96,660 & 95,717 & 95,721 & 95,231 & $\mid 95,855$ & 95,063 & 95,743 & 95,121 & 94,980 & 97,422 & 96,570 & 95,376 & 96,254 & 96,044 & 95,537 & 95,515 & 95,378 \\
\hline \multicolumn{19}{|c|}{ Fórmula estrutural calculada na base de 22 átomos de oxigênio } \\
\hline $\mathrm{Si}$ & 5,730 & 5,717 & 5,727 & 5,740 & 5,673 & 5,701 & $\mid 5,643$ & 5,711 & 5,797 & 5,796 & 5,734 & 5,825 & 5,700 & 5,799 & 5,850 & 5,920 & $\mid 5,707$ & 5,971 \\
\hline $\mathrm{Al}^{\mathrm{IV}}$ & 2,270 & 2,283 & 2,273 & 2,260 & 2,327 & 2,299 & 2,357 & 2,289 & 2,203 & 2,204 & 2,266 & 2,175 & 2,300 & 2,201 & 2,150 & 2,080 & 2,293 & 2,029 \\
\hline Sítio $T$ & 8,000 & 8,000 & 8,000 & 8,000 & 8,000 & 8,000 & 8,000 & 8,000 & 8,000 & 8,000 & 8,000 & 8,000 & 8,000 & 8,000 & 8,000 & 8,000 & 8,000 & 8,000 \\
\hline $\mathrm{Al}^{\mathrm{VI}}$ & 0,398 & 0,188 & 0,277 & 0 & 0,233 & 0,304 & 0, & 0,510 & 2 & 91 & 0,392 & 70 & 55 & 0,455 & 68 & 33 & 0,422 & 0, \\
\hline $\mathrm{Fe}$ & 1,965 & 2,037 & 1,975 & 2,022 & 2,123 & 2,067 & 1,896 & 1,906 & 1,821 & 1,754 & 1,868 & 1,875 & 1,920 & 1,944 & 1,739 & 1,686 & 1,840 & 1,550 \\
\hline $\mathrm{Mg}$ & 2,938 & 3,226 & 3,097 & 2,970 & 2,827 & 3,003 & 3,092 & 3,068 & 3,203 & 3,223 & 3,303 & 3,201 & 3,220 & 3,310 & 3,384 & 3,398 & 3,551 & 3,504 \\
\hline $\mathrm{Mn}$ & 0,036 & 0,026 & 0,049 & 0,050 & 0,051 & 0,052 & 0,026 & 0,025 & 0,024 & 0,013 & 0,043 & 0,038 & 0,036 & 0,037 & 0,037 & 0,038 & 0,031 & 0,031 \\
\hline $\mathrm{Ti}$ & 0,329 & 0,293 & 0,301 & 0,355 & 0,408 & 0,281 & 0,172 & 0,200 & 0,117 & 0,185 & 0,199 & 0,233 & 0,096 & 0,079 & 0,109 & 0,084 & 0,104 & 0,098 \\
\hline Sítio O & 5,666 & 5,770 & 5,699 & 5,657 & 5,642 & 5,707 & 5,765 & 5,709 & 5,717 & 5,694 & 5,805 & 5,717 & 5,828 & 5,825 & 5,736 & 5,739 & 5,948 & 5,692 \\
\hline $\mathrm{Ca}$ & 0,002 & 0,000 & 0,011 & 0,006 & 0,000 & 0,003 & 0,006 & 0,013 & 0,002 & 0,000 & 0,001 & 0,000 & 0,009 & 0,005 & 0,004 & 0,003 & 0,014 & 0,003 \\
\hline $\mathrm{Na}$ & 0,008 & 0,018 & 0,005 & 0,022 & 0,000 & 0,000 & 0,000 & 0,016 & 0,030 & 0,000 & 0,000 & 0,000 & 0,000 & 0,010 & 0,010 & 0,005 & 0,000 & 0,025 \\
\hline K & 1,873 & 1,950 & 1,969 & 1,942 & 1,995 & 2,011 & 1,893 & 1,918 & 1,949 & 1,866 & 1,863 & 1,904 & 1,878 & 1,918 & 1,974 & 1,889 & 1,740 & 1,910 \\
\hline Sítio A & 1,882 & 1,968 & 1,985 & 1,971 & 1,995 & 2,015 & 1,899 & 1,947 & 1,981 & 1,866 & 1,864 & 1,904 & 1,887 & 1,932 & 1,988 & 1,897 & 1,754 & 1,938 \\
\hline 1 & 0,000 & 0,179 & 0,161 & 0,130 & 1,197 & 0,429 & 0,319 & 0,139 & 0,319 & 0,561 & 0,657 & 0,202 & 0,518 & 0,380 & 0,829 & 0,675 & 0,382 & 0,591 \\
\hline $\mathrm{Cl}$ & 0,007 & 0,013 & 0,004 & 0,006 & 0,004 & 0,003 & 0,008 & 0,004 & 0,013 & 0,008 & 0,000 & 0,008 & 0,004 & 0,019 & 0,011 & 0,010 & 0,014 & 0,011 \\
\hline $\begin{array}{l}\mathrm{Mg} / \\
\mathrm{Mg}+\mathrm{Fet}\end{array}$ & 0,60 & 0,61 & 0 & 0,59 & 0 & 0 & 2 & 0 & 0,63 & 0,65 & 0 & 0,63 & 0 & 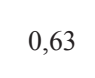 & 6 & 7 & 0,66 & 59 \\
\hline Al total & 2,67 & 2,47 & 2,55 & 2,52 & 2,56 & 2,60 & 2,93 & 2,80 & 2,79 & 2,66 & 2,66 & 2,55 & 2,86 & 2,66 & 2,62 & 2,61 & 2,71 & 2,54 \\
\hline
\end{tabular}

Bt $1=$ Biotita 1; Bt 2= Biotita 2; Bt $3=$ Biotita 3.

deficientes no sítio intercamadas, essas características são coerentes com o ambiente hidrotermal de formação das micas estudadas. Além disso, o seu relativo enriquecimento em $\mathrm{Fe}$ e $\mathrm{Mg}$ sugere temperaturas relativamente baixas para a sua formação, possivelmente da ordem de $300^{\circ} \mathrm{C}$, admitindo-se que os dados experimentais dos autores mencionados possam ser extrapolados para micas deficientes no sítio intercamadas.
Biotita As variedades texturais de biotita foram analisadas em diversas amostras dos furos 2, 4 e 9 (Tab. 5). Todas as micas analisadas enquadram-se no campo da biotita magnesiana no diagrama $\mathrm{Mg}-\mathrm{R}^{3+}-\mathrm{R}^{2+}$ de Foster (1962) (Fig. 7a). Constatou-se, porém, uma clara relação entre as composições químicas obtidas e os tipos texturais representativos das diversas associações hidrotermais. Os conteúdos de Ti e as razões $\mathrm{Fe}_{\mathrm{t}} /\left(\mathrm{Fe}_{\mathrm{t}}+\mathrm{Mg}\right)$ apresentam uma correlação positiva, decrescendo gradual- 

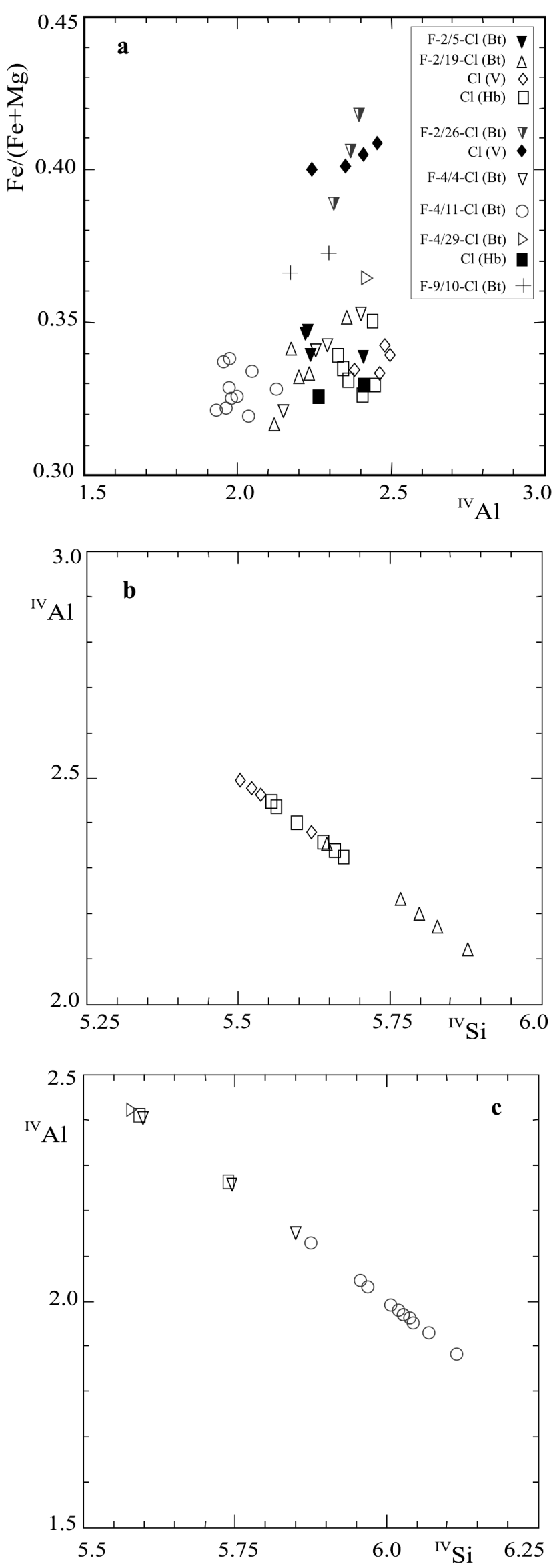

Figura 5 - $(a, b, c)$ Diagramas de variação catiônica de clorita dos testemunhos de sondagem do depósito São Jorge. mente da biotita 1 para a biotita 2 e 3 (Fig. 7b), ao passo que Ti e ${ }^{\mathrm{VI}} \mathrm{Al}$ apresentam uma correlação negativa, com o ${ }^{\mathrm{VI}} \mathrm{Al}$ aumentando da biotita 1 para a biotita 2 e 3 (Fig. 7c). No diagrama $10 * \mathrm{TiO}_{2}-\mathrm{FeO}+\mathrm{MnO}-\mathrm{MgO}$ (Fig. 7d), os três tipos texturais de biotita têm distribuições fortemente contrastantes com aparente aumento do grau de reequilíbrio no sentido da biotita do tipo 1 , interpretada como sendo formada no estágio magmático (associações 1 e 2), para o tipo 3, presente apenas nas amostras mais fortemente hidrotermalizadas (associação 4).

\section{DISCUSSÕES}

As Associações Hidrotermais e o seu Significado Thompson \& Thompson (1996) apresentam uma revisão da terminologia das associações hidrotermais que servirá de base para os termos adotados a seguir. Os dados petrográficos e a química mineral das principais fases presentes nas rochas fortemente hidrotermalizadas, quando comparados com os dados disponíveis para as rochas menos afetadas pelos processos hidrotermais, revelam que tanto o GSJA (Lamarão 2001) quanto o GSJJ mais preservado da área mineralizada foram afetados por um processo de alteração pós-magmática precoce não penetrativo (Tab. 1). Nesse processo, tanto o anfibólio como o plagioclásio, marcadores mineralógicos do estágio magmático, foram transformados. $\mathrm{O}$ anfibólio foi pseudomorfisado e substituído por clorita ( \pm biotita), carbonatos, titanita \pm óxidos de Fe e Ti e epidoto. O plagioclásio foi descalcificado e saussuritizado, com substituição parcial por sericita + epidoto \pm carbonatos. A biotita 1 ora resistiu a esse processo, ora foi parcial ou totalmente substituída, principalmente por clorita e óxidos de Fe e Ti. Não se pode afirmar com segurança se a associação 2, resultante desse processo, é um reflexo mais distante do sistema hidrotermal gerador das mineralizações ou se, simplesmente, ela reflete alterações subsolidus que afetaram o GSJA de um modo geral e, provavelmente, também o GSJJ, e que não teriam necessariamente vínculo, nem espacial, nem temporal, com os fluidos formadores do minério.

A associação 3, formada durante o estágio de alteração propilítica, é marcada pela desestabilização do epidoto, que geralmente desaparece da rocha. Essa transformação gera uma zona enriquecida em clorita e plagioclásio descalcificado (albítico), caracterizada pela presença de rochas avermelhadas que preservam a textura granítica, mas cuja associação magmática foi profundamente modificada. Essas rochas contém, por vezes, teores expressivos de pirita e ouro. Elas associam-se de modo íntimo com as zonas mais intensamente hidrotermalizadas (associação 4).

A associação 4 concentra as mineralizações e é definida pela associação de illita + carbonatos + pirita \pm clorita \pm biotita 3 , correspondendo, de modo geral, a uma associação fílica. A hipótese de se tratar de uma associação argílica intermediária parece menos provável devido à pouca expressão de minerais argilosos nos testemunhos estudados. Alternativamente, poderia se tratar de uma alteração fílica com superimposição de uma alteração por carbonatação. Essa alternativa 

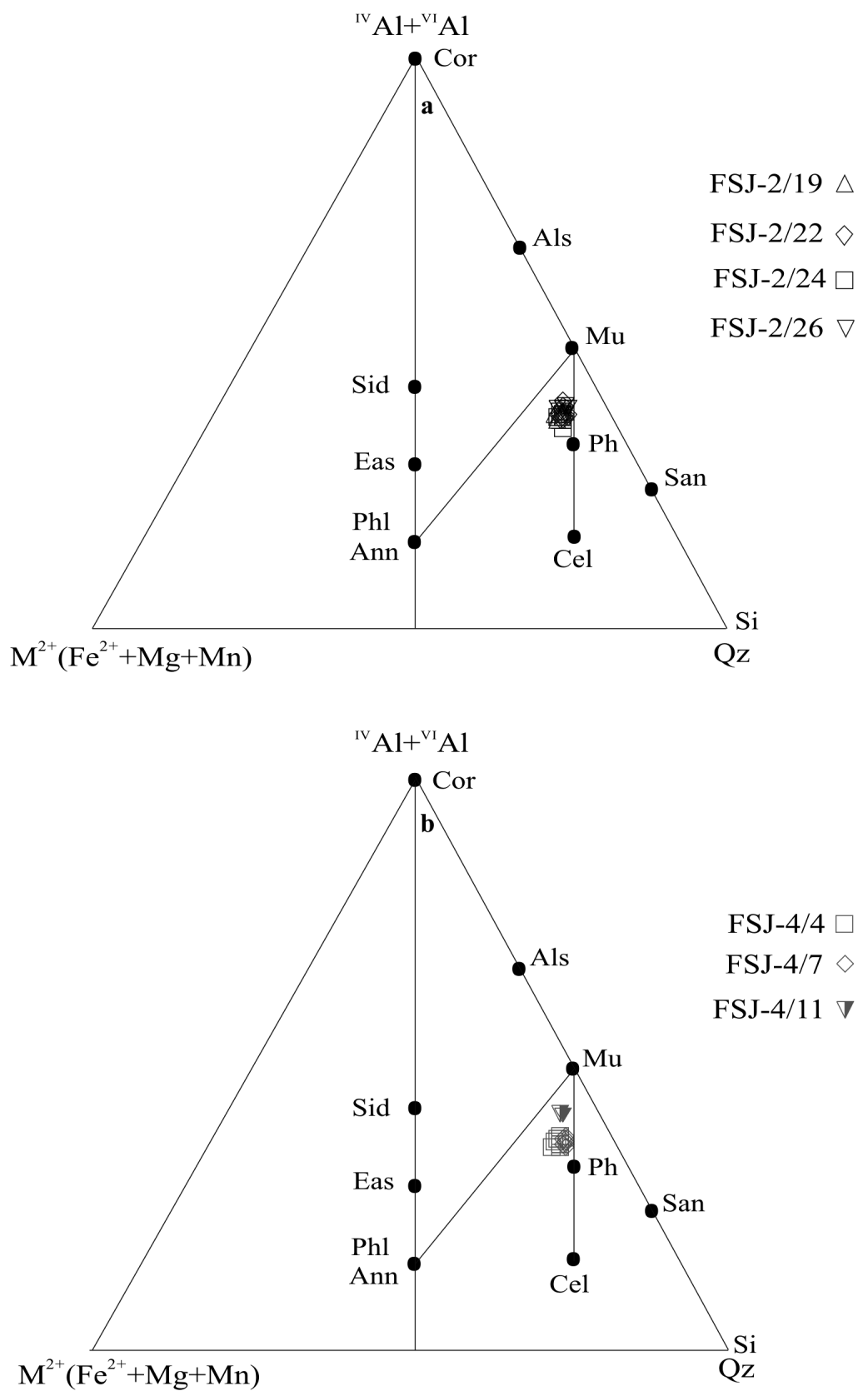

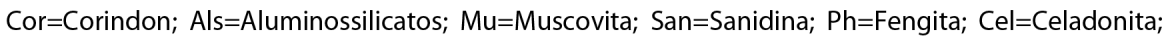
Ann=Anita; Phl=Flogopita; Eas=Eastonita; Sid=Siderofilita; Qz=Quarto

Figura 6 - Diagrama Alt - $\mathrm{M}^{2+}$ - Si (Monier \& Robert 1986) para as micas brancas dos testemunhos de sondagem dos furos 02 (a) e 04 (b) da área mineralizada do depósito São Jorge.

não pode ser inteiramente descartada, mas as evidências petrográficas sugerem que illitas e carbonatos formaram-se senão simultaneamente, pelo menos em intervalos de temperatura parcialmente superpostos, e sempre nas zonas mais intensamente afetadas pelos fluidos. Conforme assinalado no estudo dos processos hidrotermais associados ao Granito Matupá (Moura 1998), nem sempre é possível ser conclusivo sobre as relações entre as várias associações hidrotermais. Mason (inédito) também destaca o fato de a alteração por carbonatação ser geralmente episódica, mas podendo se estender ao longo de toda a seqüência de eventos hidrotermais, obscurecendo e tornando confusas as relações nas zonas mais intensamente hidrotermalizadas. De qualquer modo, fluidos ricos em $\mathrm{CO}_{2}$ seriam muito provavelmente responsáveis pela desestabilização do epidoto (Mexias et al. 1990) e teriam um papel decisivo no transporte e deposição de sulfetos e ouro.

Os intervalos de temperatura em grande parte superpostos sugeridos pelo geotermômetro da clorita 

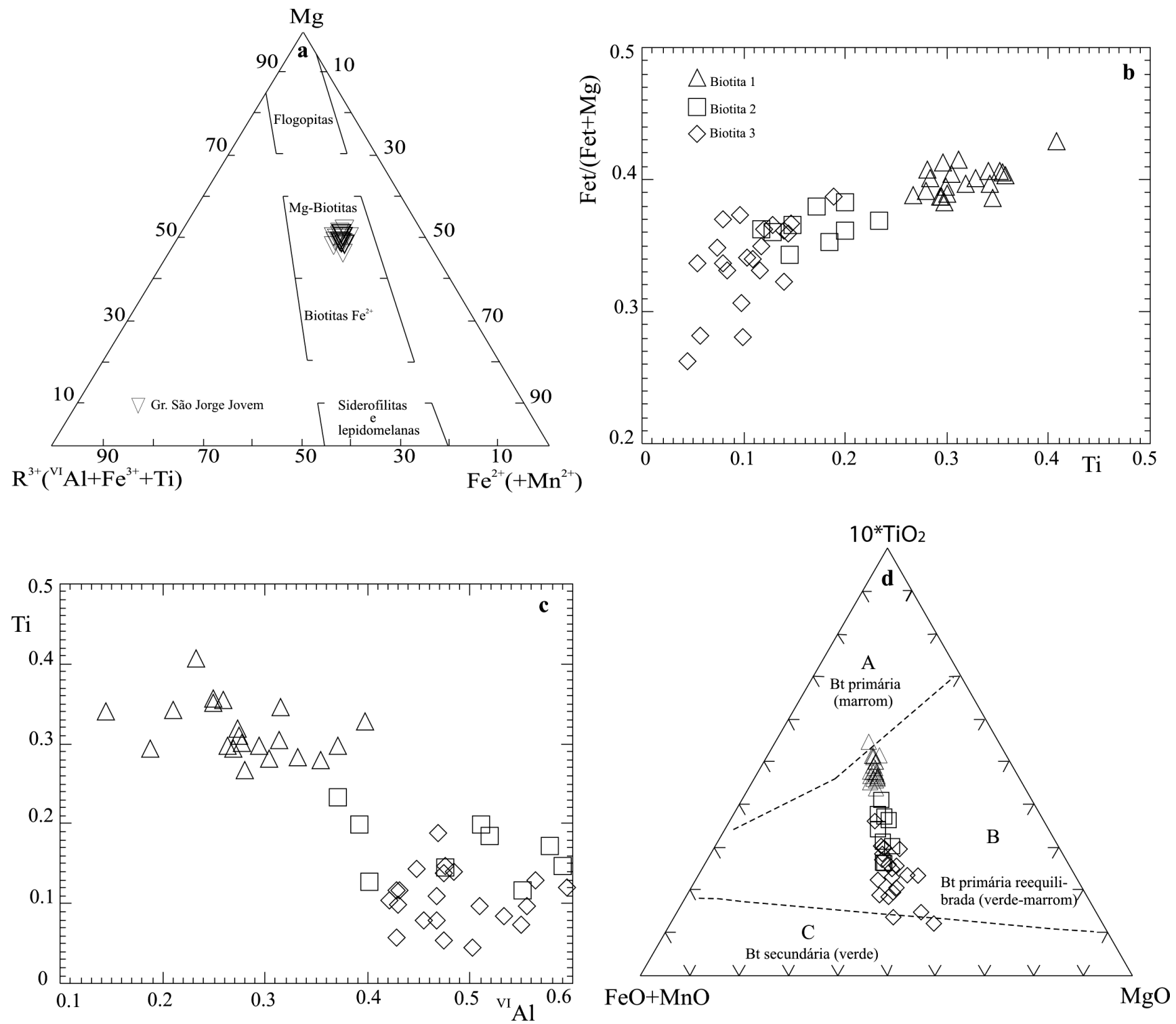

Figura 7 - a. Diagrama de classificação $M g-R^{2+}-R^{3+}$ (Foster 1960), b. Diagrama Fe/(Fe + Mg)-Ti, c. Diagrama $\mathrm{Ti}-{ }^{V I} \mathrm{Al}$, d. Diagrama $10 * \mathrm{TiO}_{2}-\mathrm{FeO}+\mathrm{Mn}-\mathrm{MgO}$ (Nachit 1986, óxidos em \% em peso).

indicam que as rochas avermelhadas que envelopam as zonas de alteração fílica, em geral mais intensamente deformadas e brechadas, são muito provavelmente relacionadas a um mesmo processo hidrotermal, com a zona de alteração propilítica correspondendo à porção mais externa e de diluição gradual dos fluidos, ao passo que a zona de alteração fílica seria aquela na qual o fluxo dos fluidos seria mais intenso, permitindo que a transformação da rocha granítica fosse mais profunda e maior a concentração de minério.

\section{Condições de Formação das Associações Hidrotermais} TEMPERATURA O geotermômetro proposto por $\mathrm{Ca}-$ thelineau (1988) indicou temperaturas de $300 \pm 40^{\circ} \mathrm{C}$ para a formação da clorita presente nas associações 3 e 4 , representativas portanto das principais associações identificadas na zona mineralizada. Temperaturas similares foram obtidas em estudo de inclusões fluidas em quartzo de veio dessas mesmas rochas (Ronchi et al. 2000). Os conteúdos relativamente elevados de $\mathrm{FeO}$ e $\mathrm{MgO}$ na illita das rochas hidrotermalizadas indicam que nesse aspecto ela se aproxima das fengitas, o que sugere temperaturas relativamente baixas para a formação da mesma (Monier \& Robert 1986) e, provavelmente, próximas daquelas estimadas com base no geotermômetro da clorita.

Sabe-se que existe uma relação clara entre conteúdo de Ti e temperatura de formação de biotita (Dymek 1983). No caso das rochas hidrotermalizadas do depósito São Jorge constatou-se um acentuado decréscimo em Ti das denominadas biotita 1, magmática, para as biotitas 2 e 3, hidrotermais (Lamarão \& Dall'Agnol 2004). Estas evidências, embora não permitam deduzir valores para as temperaturas de formação dos vários tipos texturais de biotita, demonstram que as referidas gerações de biotita formaram-se, do tipo 1 para o 3, em temperaturas nitidamente decrescentes. Isto reforça o 
esquema evolutivo proposto para as diferentes associações minerais identificadas nas rochas da área mineralizada e as deduções feitas com base na clorita e illita.

PRESSÃO Os baixos conteúdos de $\mathrm{Al}$ total nos anfibólios do granito hospedeiro das mineralizações (Lamarão \& Dall'Agnol 2004) sugerem que o mesmo formou-se a pequenas profundidades, ao que tudo indica a pressão de no máximo 1 kbar. Porém, a possibilidade de reequilíbrio subsolidus e o fato de diversos autores não recomendarem a aplicação do geobarômetro para anfibólios com conteúdos muito baixos de $\mathrm{Al}$ (Johnson \& Rutherford 1989, Schmidt 1992) limita a aplicação do mesmo. Entretanto, pressões um pouco mais elevadas, da ordem de 1 a 2 kbar, são sugeridas pela composição dos anfibólios para a cristalização do anfibólio-biotita-monzogranito dominante no corpo e associado ao GSJA (Lamarão 2001). Como o contexto tectônico favoreceria um soerguimento durante o período de 100 milhões de anos que separa a colocação dos granitos São Jorge Antigo e Jovem, mesmo considerando a possibilidade de reequilíbrio subsolidus dos anfibólios do GSJJ, tudo indica que a colocação final deste se deu a baixas pressões, da ordem de 1 kbar. Pressões da ordem de 1 kbar também foram deduzidas a partir do estudo de inclusões fluidas em quartzo da zona mineralizada (Ronchi et al. 2000).

FUGACIDADE DE OXIGÊNIO As composições de anfibólio (Lamarão \& Dall'Agnol 2004) e biotita magmática (Fig. 7a) revelam, pelas suas altas razões $\mathrm{Mg}$ / $\left(\mathrm{Mg}+\mathrm{Fe}_{\mathrm{t}}\right)$, que as rochas do GSJJ, portadoras das mineralizações, evoluíram no estágio magmático em condições relativamente oxidantes. Neste estágio, as rochas da associação 1 da área mineralizada, assim como as diversas fácies do GSJA, cristalizaram em condições relativamente oxidantes, próximas daquelas definidas pelos tampões NNO e HITMQ (Figueiredo 1999).

Quanto ao estágio hidrotermal, há evidências de oxidação intensa na zona mineralizada. A principal delas é a desestabilização da magnetita, com sua corrosão e sua substituição parcial por hematita (Figueiredo 1999). A abundância de carbonatos, revelando elevada atividade do $\mathrm{CO}_{2}$, também indica isso. Logo, em termos preliminares, podem ser estimadas condições de fugacidade de oxigênio superiores às dos tampões mencionados anteriormente, tendendo a se aproximar ou mesmo atingindo as condições do tampão HM.

Comparações com Outras Áreas e Possíveis Modelos para a Gênese das Mineralizações Em termos da PAT, as associações hidrotermais presentes no depósito São Jorge diferem acentuadamente daquelas descritas por Dreher et al. (1998) nos garimpos Davi e Joel, onde predomina a alteração potássica caracterizada pela formação marcante de adulária. Esse mineral e a alteração potássica não têm expressão marcante na área estudada. Juliani et al. (2002) descrevem quatro estágios de alteração hidrotermal associados à mineralização de Au no Granito Batalha: metassomatismo sódico, com forma- ção de albita intersticial e substituição dos feldspatos; metassomatismo potássico, com cristalização de biotita e feldspato alcalino; propilitização, caracterizada pela paragênese epidoto-clorita-albita-carbonatos-sulfeto; sericitização, associada a quartzo e sulfetos. Apesar de algumas semelhanças, na área mineralizada do GSJJ não foi observado metassomatismo sódico e potássico. Em alguns garimpos da província, como São Domingos e São Chico, Klein et al. (1999) descrevem associações propíliticas em que o epidoto aparece geralmente com destaque. Isso constitui uma diferença significativa em relação ao depósito estudado. Porém, como não foram desenvolvidos estudos mais detalhados sobre as associações hidrotermais da quase totalidade das áreas mineralizadas da província, não se pode ser muito conclusivo a esse respeito. Existe a possibilidade de que a alteração propilítica, presente no GSJA e, localmente, na zona hidrotermal que envolve a zona fílica do depósito São Jorge, seja de fato de ocorrência generalizada na província. Entretanto, parece claro que, na PAT, os níveis mais ricamente mineralizados não são relacionados com a zona de alteração propilítica e sim com a zona fílica (caso do depósito São Jorge, este trabalho; depósitos do tipo intrusion-related de Santos et al. 2001; depósito Batalha, Juliani et al., 2002). Resumindo, os dados disponíveis sugerem que as associações hidrotermais da província mostram variações expressivas, não se enquadrando num único tipo.

Os modelos genéticos aventados para explicar as mineralizações de ouro da província também são variados, incluindo desde depósitos do tipo mesotermal (Coutinho et al. 2000, Klein et al. 1999) a epitermal (Dreher et al. 1998, Jacobi 1999, Corrêa-Silva et al. 2000, Juliani et al. 2000, 2005, Nunes 2001, Landis et al. 2005), com possíveis associações do tipo pórfiro (Coutinho et al. 1998). Juliani et al. (2002) entendem que o Granito Batalha partilha características com depósitos relacionados a intrusões e do tipo $\mathrm{Cu}$-Au porfirítico, e sugerem um modelo híbrido, tipo $\mathrm{Cu}-\mathrm{Au}$ porfirítico. Analogias com os depósitos do tipo Olympic Dam também foram sugeridas (Jacobi 1999), porém a maioria dos autores (cf. Santos et al. 2001) enquadra os depósitos nos tipos orogênico (Groves et al. 1998) e intrusion-related (Sillitoe 1991). A identificação na PAT de depósitos paleoproterozóicos do tipo epitermal High-Sulfidation alojados em sequências vulcânicas demonstrou definitivamente a importância de depósitos epitermais na província (Juliani et al. 2000, 2005, Nunes 2001, Landis et al. 2005). Com isto tende a se reduzir a controvérsia entre a dominância de depósitos do tipo mesotermal ou epitermal, com diversos autores admitindo um ambiente capaz de abrigar ambos os tipos de depósitos (Coutinho et al. 2000, Klein et al. 2001). Por outro lado, um modelo do tipo Olympic Dam não parece adequado para explicar as características dominantes nos depósitos da província.

O depósito São Jorge poderia estar relacionado a intrusões de granitos porfiríticos, rochas bastante frequentes na região (Lamarão 2001). No entanto, um aspecto desfavorável a este modelo é a ausência de alteração potássica nas suas assembléias hidrotermais. 
Santos et al. (2001) enquadram o depósito São Jorge entre os depósitos epizonais do tipo disseminado/stockwork, intrusion-related. As evidências disponíveis sugerem que o depósito São Jorge formou-se à pequena profundidade e sob baixa pressão, sendo associado com deformação dúctil-rúptil. Por outro lado, apesar da ausência de magnetita hidrotermal ele também apresenta similaridades com depósitos do tipo porfirítico com $\mathrm{Au}$ (Sillitoe 1991), devido ao estilo da mineralização, disseminada, hospedada em granitóides.

No depósito de Serrinha, associado ao Granito Matupá, na Província Juruena, foi identificada uma série de processos hidrotermais sobrepostos e de difícil individualização, incluindo microclinização, albitização com formação de aegirina associada, alteração sericítica, cloritização, piritização e carbonatação (Moura 1998). Eles diferem dos processos observados no depósito São Jorge, sobretudo pela maior importância da alteração potássica. Em Serrinha, as micas brancas analisadas são da série muscovita-fengita e não micas deficientes de carga no sítio intercamadas, do tipo illita. As temperaturas obtidas para a clorita se superpõem, de modo geral, àquelas obtidas no presente estudo, embora haja uma associação de temperatura entre 347 e $386^{\circ} \mathrm{C}$, superior àquelas sugeridas pelo geotermômetro para a clorita de São Jorge. Há, portanto, algumas analogias entre os processos hidrotermais identificados nos dois depósitos, embora não exista uma correspondência perfeita.

Os processos observados no depósito São Jorge guardam muitas analogias com o descrito por Mexias et al. (1990) na área de Volta Grande, associada com o Granito Lavras (RS). A alteração sericítica é marcante nos sistemas hidrotermais de ambos, causando a desestabilização do epidoto formado no estágio de alteração propilítica e levando à deposição de sulfetos. A clorita estudada por aqueles autores indicou temperaturas de formação entre $279 \pm 20{ }^{\circ} \mathrm{C}$ e $319 \pm 12{ }^{\circ} \mathrm{C}$, similares, portanto, àquelas do depósito São Jorge, e também não mostram diferenças expressivas de temperaturas de formação, independente do seu tipo textural. Em São Jorge, porém, houve uma menor tendência à preservação ou desenvolvimento da clorita durante o estágio de alteração fílica, sugerindo que a atividade de $\mathrm{H}^{+}$foi comparativamente mais elevada que em Volta Grande, permitindo uma lixiviação mais eficaz de $\mathrm{Fe}$ e $\mathrm{Mg}$ e dificultando a formação ou preservação da clorita.

CONCLUSÕES O estudo da área mineralizada do Granito São Jorge permitiu a caracterização de quatro associações minerais: a associação 1 corresponde à assembléia magmática primária, comparativamente pouco transformada, tendo como minerais mais representativos o anfibólio e o plagioclásio andesina-oligoclásio; a associação 2 é similar à anterior, porém nela o anfibólio encontra-se inteiramente pseudomorfisado, o plagioclásio mais intensamente saussuritizado e a biotita parcialmente alterada; as associações 3 e 4 são aquelas efetivamente associadas aos processos geradores das mineralizações; a associação 3, do tipo propilí- tica, corresponde a granitos fortemente hidrotermalizados de cor avermelhada, enriquecidos em clorita, com biotita, anfibólio e plagioclásio primário inteiramente substituídos, mas preservando a textura original da rocha; a associação 4 é do tipo fílica, com carbonatação superimposta ou associada, destacando-se illitas e carbonatos, estando presente em rochas cuja textura original foi muitas vezes obliterada. A pirita é o sulfeto predominante na zona mineralizada, sendo acompanhada por calcopirita, esfalerita e, muito raramente, galena e molibdenita. O ouro associa-se com a pirita, ocorrendo incluso ou em fraturas na mesma.

Os geotermômetros de clorita, os elevados conteúdos de $\mathrm{Fe}$ e $\mathrm{Mg}$ das illitas e os baixos conteúdos de Ti das biotitas tardias indicam temperaturas em torno de $300 \pm 40{ }^{\circ} \mathrm{C}$ para a formação das associações 3 e 4 . Os baixos conteúdos de Al total nos anfibólios dos granitos da associação 1 indicam baixas pressões para a formação dos granitos portadores das mineralizações, porém não permitem definir esta pressão com rigor. A fugacidade reinante na zona hidrotermalizada foi elevada, bem superior às condições próximas dos tampões NNO e HITMQ estimadas para os granitos encaixantes das mineralizações (Figueiredo 1999).

A alteração fílica com carbonatação intensa associada observada em São Jorge, difere daquela descrita nos garimpos Joel e Davi (Dreher et al. 1998) e o desequilíbrio do epidoto na zona mineralizada contrasta com a frequente ocorrência expressiva desse mineral em muitos depósitos do Tapajós (Klein et al. 1999). Isso evidencia que os estilos de alteração hidrotermal com mineralizações auríferas associadas na província foram bastante diversificados, embora estudos detalhados em um número maior de áreas sejam indispensáveis para uma conclusão definitiva. O depósito São Jorge poderia corresponder a um modelo do tipo pórfiro ou, eventualmente, do tipo intrusion-related. Os dados disponíveis não indicam analogias do mesmo com depósitos do tipo Olympic Dam. Os processos hidrotermais observados em São Jorge guardam algumas semelhanças com aqueles descritos no depósito de Serrinha (Moura 1998) e no Granito Batalha (Juliani et al. 2002), mas se aproximam ainda mais do sistema hidrotermal de Volta Grande (Mexias et al. 1990).

Agradecimentos A empresa RTDM, que permitiu livre acesso e amostragem na área do projeto, cedeu informações inéditas através de sua equipe (P.S.L. Jacobi, M. Pinto, E. Pereira, A.W. Borges) e contribuiu financeiramente para o desenvolvimento do projeto. A empresa Target Mineração e o DNPM contribuíram financeiramente. A maioria dos recursos utilizados foram fornecidos pelo convênio PADCT/FINEP/FADESP (88.98.0400.00). A ADIMB articulou a proposta inicial e incentivou o desenvolvimento da pesquisa. $\mathrm{O}$ IG-UFPA forneceu facilidades laboratoriais. A. Mexias e L.H. Ronchi colaboraram através de discussões sobre os processos hidrotermais e fluidos. O Laboratório de Microssonda Eletrônica do IG/UFRGS forneceu apoio nas análises de minerais. Este trabalho é uma 
contribuição ao Instituto Nacional de Ciência e Tecnologia de Geociências da Amazônia (CNPq, processo
573733/2008-2). Aos revisores da RBG pelas sugestões e críticas ao manuscrito.

\section{Referências}

Almeida M.E, Brito M.F.L, Ferreira A.L, Monteiro M.A.S. 2000. Geologia e Recursos Minerais da Folha Mamãe Anã (SB.21-V-D). Estados do Amazonas e Pará. Escala 1:250.000. Nota explicativa. Projeto Especial Província Mineral do Tapajós. Brasília: PROMIM Tapajós/CPRM.

Bailey S.W. 1980. Summary of recommendations of the AIPEA Nomenclature Committee. Can. Mineral., 18:143-150

Botelho N.F. \& Moura M.A. 1998. Granite-ore deposit relationship in central Brazil. J. South Am. Earth Sci., 11(5):427-438.

Botelho N.F., Moura M.A., Teixeira L.M., Olivo G.R., Cunha L.M., Santana M.U. 2005. Caracterização geológica e metalogenética do depósito de $\mathrm{Cu} \pm(\mathrm{Au}, \mathrm{W}, \mathrm{Mo}, \mathrm{Sn})$ Breves, Carajás. In: Marini O.J., Queiroz E.T., Ramos B.W. (eds.) Caracterização de Depósitos Minerais em Distritos Mineiros da Amazônia. Capítulo VI, DNPM, CT-Mineral/ FINEP, ADIMB, 56 p., CD-Rom.

Cathelineau M. 1988. Cation site occupancy in the chlorites and illites as a function of temperature. Clay Minerals, 23:471-485.

Corrêa-Silva R.H., Juliani C., Nunes C.M.D., Bettencourt J.S. 2000. Petrographic characterization of the hydrothermal alteration zones associated with gold mineralization in granitic rocks of the Batalha Gold Field, Tapajós (Pará), Brazil. Rev. Bras. Geoc., 30(2):242-245.

Coutinho M.G.N., Santos J.O.S., Fallick A.E., Lafon J.M. 2000. Orogenic gold deposits in Tapajós Mineral Province, Amazon, Brazil. In: Int. Geol. Congr., $31^{\text {st }}$, Rio de Janeiro (RJ). Abstracts volume, CD-Rom.

Dreher A.M., Vlach S.R.F., Martini S.L. 1998. Adularia associated with epithermal gold veins in the Tapajós Mineral Province, Pará state, northern Brazil. Rev. Bras. Geoc., 28:397-404

Dymek R.F. 1983. Titanium, aluminium and interlayer cation substitutions in biotite from high-grade gnaisses, West Greenland. Am. Mineral., 68:880-899.

Faraco M.T.L., Carvalho J.M.A., Klein E.L. 1997. Carta Metalogenética da Província Aurífera do Tapajós. In: Costa M.L. \& Angélica R.S. (eds.) Contribuições à Geologia da Amazônia. Belém, FINEP, SBG - NO, p. 423-437.

Figueiredo M.A.B.M. 1999. Minerais óxidos de Fe e Ti e Suscetibilidade Magnética em vulcânicas e granitóides Proterozóicos de Vila Riozinho, Província Aurífera do Tapajós. Dissertação de Mestrado, Centro de Geociências, Universidade Federal do Pará, 171p.

Foster M.D. 1962. Interpretation of the composition of trioctahedral micas. Washington: U. S. Departament of the Interior. Geol. Surv. Prof. Paper, 414-A., 33 p.

Groves D.I., Goldfar R.J., Gebre-Mariam M., Hegemann S.G., Robert F. 1998. Orogenic gold deposits: a proposed classification in the context of their crustal distribution and relationship to other gold deposit types. Ore Geol.
Rev., 13:7-27.

Jacobi P. 1999. The discovery of epithermal Au-Cu-Mo Proterozoic deposits in the Tapajós Province, Brazil. Rev. Bras. Geoc., 29:277-279.

Johnson M.C. \& Rutherford M.J. 1989. Experimental calibration of the aluminium-in-hornblende geobarometer with application to Long Valley caldera (California) volcanic rocks. Geology, 17:837-841.

Juliani C.A., Corrêa-Silva R.H.A., Monteiro L.V.S.A., Bettencourt J.S., Nunes C.M.D.A. 2002. The Batalha Augranite system-Tapajós Gold Province, Amazonian craton, Brazil: hydrothermal alteration and regional implications. Precambrian Res., 119:225-256.

Juliani C., Monteiro L.V.S, Bettencourt J.S., Corrêa Silva R.H. 2004a. Paleoproterozoic epithermal high- and lowsulfidation and porphyry-related $\mathrm{Au}$ mineralizations in the Tapajós Gold Province, Brazil: exploration prospectives. In: Simpósio Brasileiro de Exploração Mineral, Ouro Preto: ADIMB/DNPM/SBGf/SBG, CD-Rom.

Juliani C., Bettencourt J.S., Monteiro L.V.S. 2004b. Modelos conceituais de depósitos paleoproterozóicos high- e low-sulfidation ( $\mathrm{Au} ; \mathrm{Cu}-\mathrm{Mo} \pm \mathrm{Au}$ ) e do tipo pórfiro (Au$\mathrm{Cu} ; \mathrm{Cu}-\mathrm{Mo}$ ) na Província Aurífera do Tapajós (PA). In: Congresso Brasileiro de Geologia, 42, Araxá, Anais, CD-Rom.

Juliani C., Rye R.O, Nunes C.M.D, Snee L.W, Corrêa Silva, R.H., Monteiro L.V.S, Bettencourt J.S, Neumann R., Alcover A. 2005. Paleoproterozoic high-sulfidation mineralization in the Tapajós gold province, Amazonian Craton, Brazil: geology, mineralogy, alunite argon age, and stable-isotope constraints. Chem. Geol., 215:95-125.

Juliani C.A., Nunes C.M.D., Bettencourt J.S., Silva R.M.C., Monteiro L.V.S.M., Neumann R., Alcover Neto A., Rye E.O. 2000. Early Proterozoic volcanic-hosted quartz-allunite epithermal deposit in the Tapajós Gold Province, Amazonian Craton, Brazil. In: GSA Annual Meeting, Reno, Nevada, A-49.

Klein E.L. \& Vasquez M.L. 2000. Geologia e recursos minerais da Folha Vila Riozinho - SB.21-Z-A. Estado do Pará Escala 1:250.000. Nota explicativa. In: Klein E.L. (ed.) Projeto Especial Província Mineral do Tapajós. PROMIM Tapajós/CPRM, Brasília, CD-Rom.

Klein E.L., Vasquez M.L., Santos R.A., Costa L.T.R. 1999. Geologia e controle estrutural das mineralizações auríferas na Folha Vila Riozinho e NW da Folha Rio Novo, Província Tapajós. In: SBG, Simp Geol. Amaz., 6, Boletim de resumos expandidos, p. 128-131.

Klein E.L., Santos R.A., Fuzikawa K., Angélica R.S. 2001. Hydrothermal fluid evolution and structural control of the Guarim gold mineralization, Tapajós Province, Amazonian Craton, Brazil. Miner. Depos., 36(2):149-164.

Lamarão C.N. 2001. Geologia, Geoquímica e Geocronologia do Magmatismo Paleoproterozóico da Região de Vila Riozinho, Província Aurífera do Tapajós, Cráton 
Amazônico. Tese de Doutoramento, Centro de Geociências, Universidade Federal do Pará, 285p.

Lamarão C.N. \& Dall'Agnol R. 2004. Química mineral de anfibólios e biotitas e condições de cristalização de granitóides paleoproterozóicos da região de Vila Riozinho, Província Aurífera do Tapajós, Cráton Amazônico. Rev. Bras. Geoc., 34(1):95-108.

Lamarão C.N., Dall'Agnol R., Lafon J.M., Lima E.F. 2002. Geology, geochemistry and $\mathrm{Pb}-\mathrm{Pb}$ zircon geochronology of the Paleoproterozoic magmatism of Vila Riozinho, Tapajós Gold Province, Amazonian craton, Brazil. Precambrian Res., 119:189-223.

Lamarão C.N., Dall'Agnol R., Pimentel M.M. 2005. Nd Isotopic composition of Paleoproterozoic volcanic and granitoid rocks of Vila Riozinho: Implications for the crustal evolution of the Tapajós Gold Province, Amazon craton. J. South Am. Earth Sci., 18:277-292.

Landis G.P., Snee LW., Juliani C. 2005. Evaluation of alunite argon ages and fluid inclusion integrity: step-wise noble gas heating experiments on $1.87 \mathrm{Ga}$ alunite from Tapajós Gold Province, Brazil. Chem. Geol., 215:127-153.

Lindenmayer Z.G., Fleck A., Gomes C.H., Santos A.B.S., Caron R., Paula F.C., Laux J.H., Pimentel M.M., Sardinha A.S. 2005. Caracterização geológica do alvo Estrela (Cu-Au), Serra dos Carajás, Pará. In: Marini O.J., Queiroz E.T., Ramos B.W. (eds.) Caracterização de Depósitos Minerais em Distritos Mineiros da Amazônia. Capítulo IV, DNPM, CT-Mineral/FINEP, ADIMB, 74p, CD-Rom.

Mexias A.S., Formoso M.L.L., Meunier A., Beaufort D. 1990. O sistema hidrotermal fóssil de Volta Grande, Lavras do Sul/RS. Parte I. Petrografia do hidrotermalismo. Geoch. Bras., 4(2):139-157.

Monier G. \& Robert J.L. 1986. Muscovite solid solutions in the system $\mathrm{K}_{2} \mathrm{O}-\mathrm{MgO}-\mathrm{FeO}-\mathrm{Al}_{2} \mathrm{O}_{3}-\mathrm{SiO}_{2}-\mathrm{H}_{2} \mathrm{O}$ : an experimental study at 2 kbar $\mathrm{P}_{\mathrm{H} 2 \mathrm{O}}$ and comparison with natural Li-free whitemicas. Mineral. Mag., 50:257-266.

Moura M.A. 1998. O maciço granítico Matupá e o depósito de ouro de Serrinha (MT): petrologia, alteração hidrotermal e metalogenia. Tese de Doutoramento, Instituto de Geociências, Universidade de Brasília, 238 p.

Moura M.A., Botelho, N.F., Olivo G.R., Kyser T.K. 2006. Granite-related paleoproterozoic Serrinha gold deposit, Southern Amazonia, Brazil: Hydrothermal alteration, fluid inclusion and stable isotopic constraints on genesis and evolution. Econ. Geol., 101(3):85-605.

Nachit H. 1986. Contribution à l'étude analytique et expérimentale des biotites des granitoïdes. Applications typologiques. Tese de Doutoramento, Université de Bretagne Occidentale, $181 \mathrm{p}$.

Nunes C.D. 2001. Caracterização de um sistema epitermal High Sulfidation Paleoproterozóico na Província Aurífera do Tapajós, Pará. Dissertação de Mestrado, Instituto de Geociências, Universidade de São Paulo, $174 \mathrm{p}$.

Rieder M., Cavazzini G., D’yakonov S., Frank-Kamenetski
V.A., Gottardi G., Guggenheimis S., Koval P.V., Müller G., Neiva A.M.R., Radoslovich E.W., Robert J.L., Sassi F.P., Takeda H., Weiss Z., Wones D.R. 1998. Nomenclature of the micas. Clays and Clay Minerals, 46(5):586-595.

Ronchi L.R., Dall'Agnol R., Lamarão C.N., Borges R.M.K. 2000. Fluid inclusions in the gold deposit of the São Jorge Granite, Tapajós, Brazil. In: Int. Geol. Congr., $31^{\text {st }}$, Abstracts volume, CD-ROM.

Santos J.O.S., Hartmann L A., Gaudette H.E., Groves D.I., McNaughton N.J., Fletcher I.R. 2000. A new understanding of the Provinces of the Amazon Craton based on integration of field and U-Pb and $\mathrm{Sm}-\mathrm{Nd}$ geochronology. Gond. Res., 3:453-488.

Santos J.O.S., Groves D.I, Hartmann L.A., Moura M.A., McNaughton N.J. 2001. Gold deposits of the Tapajós and Alta Floresta domains, Tapajós-Parima orogenic belt, Amazon Craton, Brazil. Miner. Depos., 36:278-299.

Santos J.O.S., Breemen O.B.V., Groves D.I., Hartmann L.A., Almeida M.E., McNaughton N.J., Fletcher I.R., 2004. Timing and evolution of multiple Paleoproterozoic magmatic arcs in the Tapajós Domain, Amazon Craton: constraints from SHRIMP and TIMS zircon, baddeleyite and titanite U-Pb geochronology. Precambrian Res., 131(1/2):73-109.

Schmidt M.W. 1992. Amphibole composition in tonalites as a function of pressure: an experimental calibration of the Al-in-hornblende barometer. Contrib. Mineral. Petrol., 110:304-310.

Sillitoe R.H. 1991. Intrusion-related gold deposits. In: Foster R.P. (ed.) Gold Metallogeny and exploration. Glasgow, Blackie \& Son, p. 165-209.

Tallarico F.H.B., McNaugton N.J., Groves D.I., Fletcher, I.R., Figueiredo B.R., Carvalho J.B., Rego J.L., Nunes A.R. 2004. Geological and SHRIMP II U-Pb constraints on the age and origin of the Breves $\mathrm{Cu}-\mathrm{Au}-(\mathrm{W}-\mathrm{Bi}-\mathrm{Sn})$ deposit, Carajás, Brazil. Miner. Depos., 39:68-86.

Tassinari C.C.G. \& Macambira M.J.B. 1999. Geochronological Provinces of the Amazonian Craton. Episodes, 22:174-182.

Thompson A.J.B. \& Thompson J.F.H. (eds.) 1996. Atlas of alteration. St. John's. Special Publication. Geological Association of Canada, Mineral Deposits Division, 118p.

Vasquez M.L., Klein E.L., Quadros M.L.E., Bahia R.B.C., Santos A., Ricci P., Sachett C.R., Silva C.M.G., Macambira M.J.B. 1999. Magmatismo Uatumã na Província Tapajós - Novos dados geocronológicos. In: SBG, Simp. Geol. Amazônia, 6, Manaus, Boletim de resumos expandidos, p. 471-474.

Zang W. \& Fyfe W.S. 1995. Chloritization of the hydrothermally altered bedrock at the Igarapé Bahia gold deposit, Carajás, Brazil. Miner. Depos., 30:30-38.

Manuscrito ID 13403 Submetido em 05 de fevereiro de 2009 Aceito em 25 de junho de 2009 